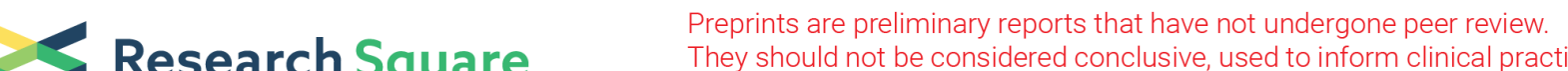 $\begin{array}{ll}\text { Research Square } & \text { They should not be considered conclusive, used to inform clinical practice, } \\ \text { or referenced by the media as validated information. }\end{array}$
}

\section{A Characterization of Laser Cleaning Painting Layer From Steel Surface Based on Thermodynamic Model}

\author{
yao lu \\ Harbin Institute of Technology \\ ye ding (D848590071@qq.com ) \\ Harbin Institute of Technology \\ maolu wang \\ Harbin Institute of Technology \\ lijun yang \\ Harbin Institute of Technology \\ yang wang \\ Harbin Institute of Technology
}

\section{Research Article}

Keywords: Laser cleaning, Microstructures, Mechanical properties, Cleaning threshold, Cleaning mechanism

Posted Date: February 23rd, 2021

DOI: https://doi.org/10.21203/rs.3.rs-224748/v1

License: (c) (1) This work is licensed under a Creative Commons Attribution 4.0 International License. Read Full License

Version of Record: A version of this preprint was published at The International Journal of Advanced Manufacturing Technology on July 6th, 2021. See the published version at https://doi.org/10.1007/s00170-021-07566-6. 
A characterization of laser cleaning painting layer from steel surface based on thermodynamic model

a. Key Laboratory of Micro-systems and Micro-structures Manufacturing, Ministry of Education, Harbin Institute of Technology, Harbin 150001, China

b. School of Mechatronics Engineering, Harbin Institute of Technology, Harbin 150001, China

In this study, the environmentally friendly nanosecond ultraviolet (UV) laser is innovatively employed laser cleaning to remove the painting layer from the AH36 steel substrate. The feasibility

11 of UV laser cleaning the painting layer is innovatively proposed and it has been calculated by the 12 model theoretically, followed by elaborating the prominent interaction mechanism of UV laser 13 exactly. The initial cleaning threshold and completely cleaning threshold are $2 \mathrm{~J} / \mathrm{cm}^{2}$ and $5 \mathrm{~J} / \mathrm{cm}^{2}$, respectively. Afterwards, the UV laser cleaned surface quality is evaluated by the scanning electron

15 microscopy (SEM), energy dispersive spectroscopy (EDS), optical microscopy (OM) and optical 16 profiler (OP), respectively. The mechanical properties have enhanced dramatically after laser 17 cleaning and characterized by the Vickers hardness tester and universal testing machine. By varying laser fluences $\left(2,5,7 \mathrm{~J} / \mathrm{cm}^{2}\right)$ during laser cleaning, microstructures registering various sizes of corrugated shaped, craters and ring-shaped could be acquired. In addition, the mechanical properties analysis including rapid melting, quenching and dislocation density effects illustrates

22 strength. Thus, laser cleaning method has emerged as a favourable means to strip painting layer in

23 lieu of traditional methods for marine industry as well as this study could promote the development 24 of laser cleaning in the field of marine engineering.

25 Keywords: Laser cleaning; Microstructures; Mechanical properties; Cleaning threshold; Cleaning 26 mechanism

\footnotetext{
*Corresponding author. E-mail: dy1992hit@hit.edu.cn (Y. Ding), yljtj@hit.edu.cn (L. Yang)
} 


\section{INTRODUCTION}

In the past a few decades, surface cleaning has been attracting considerable attention in various fields including aerospace, ocean engineering, microelectronics and medicine [1-4]. With regard to the contaminants on the surface, they are mostly of oxides, paints, polymers, coatings, microorganisms and particles [5-10]. Marine ships defouling the painting layer is a significant concern, which is mainly due to the corrosion as exposed to seawater. In this regard, ships appear to experience the paint removing alongside repainting for the maintenance of shipyard. Of particular note, the above issue has been reported to cost billions of dollars annually. Therefore, it is vital to strip off the painting layer from the substrate in order to repainting and extending the service life of the ship. Seen from prior studies, the traditional surface cleaning methods including the mechanical and chemical cleaning are recognized to be the most popular approaches. However, they have been reported to trigger the risks of polluting atmosphere and producing secondary wastes. Standing on this view, the laser cleaning method, emerging as a promising technique, is recognized to be an alternative to those conventional methods as it is more eco-friendly and does not need to contact cleaned surface. Depending on a host of traits including but not limited to excellent plasticity and toughness, high mechanical strength alongside light density and fair stiffness, steel, e.g. type AH36, has been widely used in ocean engineering [11-13]. However, it should be emphasized here that the service life of devices made with steel is strongly affected by marine environment as the latter contains a large amount of erosive ions and microorganisms which may collaboratively trigger the spalling of painting layer coating the exterior of steel base. What in follows, the internal steel base is degraded as the subsequent exposure continues. Thus, 
1 surface cleaning is extremely necessary as it allows to remove the old painting layer that has been

2 damaged, together with the attaching erosive substances. There so far exist extensive studies to

3 provide constructive hints for solving the above concern through laser cleaning technique. In 1974,

4 J.A. Fox pioneered a study to conduct surface cleaning upon paint layer, which was essentially

5 achieved by using a Q-switched neodymium laser [14]. It was reported that the paint layer can be

6 removed effectively under the strong photo-induced stress wave generated by the associated laser.

7 Besides, K. Liu and E. Garmire adopted different types of laser alongside varying pulse width to

8 remove the lacquer [15]. Seen from that, the Nd: YAG laser along with Q modulation was reported

9 to show the stronger removal effect in comparison to other examined lasers, i.e. $\mathrm{CO}_{2}$ laser, excimer

10 laser and continuous wave laser. More importantly, Chen et al. pointed out that the laser cleaning

11 technique may overcome the main flaw existing in conventional cleaning methods, viz. secondary

12 pollution, which was confirmed through optical microscope observation [13].

13 As is well reported, many factors including but not limited to the pulse frequency, the

14 scanning line interval, the scanning speed and the laser fluence are able to affect the efficiency of

15 laser cleaning [16-30]. According to Zhao et al., the energy incorporated in each single pulse

16 increased as the pulse frequency decreased, which would potentially trigger the plasma shielding

17 effect near the painting layer surface once the pulse energy reached to a certain value. Of particular

18 note, this resulting plasma shielding effect has a potential to cause the recession phenomenon

19 through absorbing the energy involved in lasers and accordingly, hinders the further cleaning

20 effectiveness to the painting layer [17-19]. Besides, the larger scanning line interval was reported

21 to decrease the corresponding cleaning efficiency. This may be attributed to that the increase in the 
1 scanning interval could dilute the unit received energy or fluence at the scanned region on the one

2 hand and sometimes even leads to the appearance of residual area on the second hand [20-23]. In

3 addition, the scanning speed influence the cleaning efficiency essentially through changing the

4 corresponding overlapping rate. In this regard, the larger scanning speed, the better cleaning

5 performance, and vice versa. [24,25]. Apart from the above, laser fluence has been widely

6 recognized as a predominant factor when investigating the laser cleaning effectiveness $[2,4,11$,

7 26-30]. In an early study conducted by Tian et al., two different laser fluences, namely $1.08 \mathrm{~J} / \mathrm{cm}^{2}$

8 and $4.14 \mathrm{~J} / \mathrm{cm}^{2}$, were respectively set and the higher cleaning efficiency was noted in the case of

9 larger laser fluence [4]. This has also been confirmed by a recent report [11], wherein the increase

10 in laser fluence within a certain range, from $1.19 \mathrm{~J} / \mathrm{cm}^{2}$ to $4.43 \mathrm{~J} / \mathrm{cm}^{2}$, was once again noted to help

11 improve the corresponding cleaning efficiency. The underlying reasons behind this may be that the

12 increasing fluence empowers the thermodynamic behavior of molecules and accordingly make the

13 attached contaminants easier be removed after a series of process including melting, vaporizing,

14 solidifying. As well, the larger fluence allows to produce the plasma in a quicker and more efficient

15 way, which also favors the further cleaning $[2,11]$. However, it should be emphasized here that any

16 increase in laser fluence beyond a threshold might trigger a risk of damaging the substrate. For

17 instance, such an upper bound in terms of laser fluence was reported to be about $11.9 \mathrm{~W} / \mathrm{cm}^{2}$, which

18 induces the excessive ablation of the substrate [31-33]. Together with experimental investigations,

19 numerical simulations have also been extensively carried out to understand the underlying

20 mechanism involved in laser cleaning. W.F. Zou et al. established a one-dimensional heat

21 conduction model based on the thermal stress mechanism alongside the Fourier transfer equation. 
1 Then, the process of laser cleaning was successfully simulated and the cleaning and damage

2 thresholds were so numerically predicted [34]. On the basis of heat conduction and Hertz-Knudsen

3 theory, V. Oliveira et al. developed a 2D finite element model to describe the TiC ablation effects

4 led by pulsed laser irradiation with varying laser fluence, and the corresponding results agreed well

5 with pertinent experimental values [35]. Aside from this, Vasantgadkar et al. also predicted the

6 ablation depth and temperature distribution, on account of plasma shielding effect [36]. Yue et al.

7 adopted the laser respectively shaped as rectangular and Gaussian to numerically investigate the

8 associated effect upon the cleaning efficiency [37].

9 However, it should be emphasized here that the laser employed in most of above studies were

10 infrared nanosecond laser, that usually triggers thermal induced defects, manifesting as the

11 recasting layer and the heat-affected zone (HAZ). On the other hand, the ultraviolet (UV) laser

12 may avoid these disadvantages effectively as it registers a greater photon energy and accordingly

13 is easier to break the intermolecular bonds. To the authors' knowledge, there exists very limited

14 study that adopted UV laser to clean the painting layer and more importantly, the influence led by

15 associated parameters upon cleaning efficiency is still not clear. In this study, the authors mark the

16 first in using UV laser to clean the painting layer and varying laser fluence levels ranging from 2

$17 \mathrm{~J} / \mathrm{cm}^{2}$ to $7 \mathrm{~J} / \mathrm{cm}^{2}$ were examined. Further, the resulting samples were also evaluated through Optical

18 Microscopy (OM), Field Emission Scanning Electron Microscopy (SEM), Optical Profiler (OP)

19 and mechanical measurements. 


\section{1 materials}

2

3

4

11 illustrated in Fig. 1.

A commercially sourced AH36 steel, as widely used in marine engineering, was employed as the substrate in this study, and its elementary compositions as determined by XRF technique is now presented in Table 1. A locally supplied paint comprising chlorinated rubber was used to coat the substrate twice. Note here that the inter layer (white color) registered a thickness of $70 \mu \mathrm{m}$ while the outer layer (red color) was as thick as $100 \mu \mathrm{m}$. The dimensions of specimens, as being used to experience laser cleaning and further characterization including SEM-EDS, OP and OM, were set as $40 \mathrm{~mm} \times 40 \mathrm{~mm} \times 5 \mathrm{~mm}$. In addition, another two batches of specimens, respectively sized as $40 \mathrm{~mm} \times 5 \mathrm{~mm} \times 5 \mathrm{~mm}$ and $30 \mathrm{~mm} \times 10 \mathrm{~mm} \times 2 \mathrm{~mm}$, were prepared as well for tensile and bending tests, conforming to ASTM E8 and ASTM E290. The representative samples are

\subsection{UV Laser cleaning surface treatment}

For starter, the laser cleaning process is operated in an ambient atmosphere, i.e. $\left(20^{\circ} \mathrm{C}\right)$, using a nanosecond fiber laser (Huaray, China) coupled with a two-dimensional galvanometer scanning system alongside the progressive scanning mode. The parameters in terms of employed laser were set as follows: maximum average power $=20 \mathrm{~W}$, wavelength $=355 \mathrm{~nm}$, laser pulse width $=15 \mathrm{~ns}$, and laser repetition rate $=100 \mathrm{kHz}$. Furthermore, three different laser fluences were examined, respectively corresponding to $2 \mathrm{~J} / \mathrm{cm}^{2}, 5 \mathrm{~J} / \mathrm{cm}^{2}$, and $7 \mathrm{~J} / \mathrm{cm}^{2}$.

\subsection{Surface characterization}

The morphology of resulting specimens was characterized by a digital ultra-depth-of-field microscope (Keyence, VHE-1000, Japan) and a Field-Emission Scanning Electron Microscope 
1 (FE SEM) coupled with an Energy Dispersive X-ray Spectroscope (EDS). The EDS was performed

2 to analyze the chemical compositions of laser cleaned surface and the original painting layer

3 surface. An optical profiler (OP, Zygo Corporation, USA) was adopted to evaluate the surface

4 roughness and 3D morphology. In addition, the mechanical performance, i.e. tensile and bending

5 strength, were measured through the Instron 5569 universal testing machine, which offered the

6 uniaxial tension and 3-point approach bending tests. The microhardness was determined using the

7 Vickers durometer.

\section{3. RESULTS AND DISCUSSION}

9 In order to realize the UV laser cleaning the painting layer feasibility, the underlying analysis

10 and discussion are crucial and essential factors to obtain the outstanding laser cleaned effects

11 theoretically. As for the mechanisms of UV laser cleaning, it is widely recognized that the

12 photothermal, photochemical interactions and combination of them are underscoring effects,

13 which has been expressed in various models detailly [38-45]. It is worth pointing out that during

14 the period of laser cleaning, the photochemical interactions, viz. the energy of UV laser emitted

15 photons are greater than the molecular bond energies within the material, which in turn further

16 break the molecular bonds and manifest as the cold machining. One notes from the Table 2. that

17 the detailed information as per the molecular bond energies of the painting layer. The photon

18 energy is expressed as $\mathrm{E}=\mathrm{h} \gamma=\mathrm{hc} / \lambda$, where $\mathrm{E}$ is photon energy, $\mathrm{h}$ is Planck constant, $\gamma$ and $\lambda$ are

19 frequency and laser wavelength respectively. According to the theoretical calculation, the energy

20 of $355 \mathrm{~nm}$ UV laser is $6.2 \mathrm{eV}$, which is much greater than molecular bond energies of the painting 
1 layer, thereafter inducing molecular bonds broken chemically. It is well agreed with the prior

2 mentioned theory and can be verified by theoretical calculation. From the table, it is clear that the

3 energy of photon emitted by the UV laser $(6.3 \mathrm{eV})$ is considerably greater than that most of

4 molecular single bond, such as $\mathrm{C}-\mathrm{H}$ bond registering $4.30 \mathrm{eV}$. Therefore, the adopted UV laser

5 cleaning could remove the painting layer in theory by calculation of photon energy.

$6 \quad 3.1$ Surface morphology

7 One notes from Fig. 2 that the representative images of laser cleaned surface are exhibited at

8 varying laser fluence upon the painting layer adhered on the surface of AH36 steel substrate. It is

9 noteworthy that there exists a strong smell of burning and a huge sound of vibration during the

10 period of laser cleaning, which is mainly due to the interactions of the UV laser and the painting

11 layer. Aside from this, it can also be inferred that both photothermal and photochemical reactions

12 trigger on the surface of the painting layer. It is coincidence with the aforementioned theoretical

13 analysis, namely, there exists both the photochemical and photothermal interactions showing up

14 in the laser cleaning process, along with breaking molecular bonds chemically. Typically, Fig. 2

15 (a, e, i) display the original painting layer surface before laser cleaning, while Fig. 2 (b, f, j), (c, g,

$16 \mathrm{k})$ and $(\mathrm{d}, \mathrm{h}, 1)$ indicate laser cleaned surface at varying laser fluence of $2 \mathrm{~J} / \mathrm{cm}^{2}, 5 \mathrm{~J} / \mathrm{cm}^{2}$, and 7

$17 \mathrm{~J} / \mathrm{cm}^{2}$ respectively. Interestingly, seen from the Fig. 2 (b), it can be shown that the superficial color

18 changes on the surface, viz., different from red painting layers, which is due to the fact that there

19 exist two kinds of painting layer (red and white) adhering on the substrate surface. After the laser

20 cleaning at laser fluence of $2 \mathrm{~J} / \mathrm{cm}^{2}$, the red painting layer has almost been peeled off from the

21 surface, whereas the white one left on the surface, as evident from Fig. 2 (a). This may attribute 
1 to the laser fluence cannot reach the threshold of the painting layer and the energy is not strong

2 enough to remove the painting layer directly. Notably, the laser fluence at $2 \mathrm{~J} / \mathrm{cm}^{2}$ is called initial

3 cleaning threshold. Aside from that, it worth mentioned here that there are some uncleaned areas

4 at the edge of specimen after laser cleaning, which is mainly due to the laser satisfied Gaussian

5 distribution in space, namely, the energy in the middle is evidently higher than the edges. As

6 expected, the laser fluence distributed at the edges is not strong enough to strip the painting layer,

7 which is coincide with the prior mentioned phenomena. One notes from Fig. 2 (c) that it can be

8 presented a superficial color variation from the zebra like color to bar shaped grey-black color in

9 the macro at a laser fluence of $5 \mathrm{~J} / \mathrm{cm}^{2}$. Specifically, UV laser cleaning induces a prominently

10 complete removal and manifests as a metallic luster on the surface of the substrate. This may infer

11 that improving the laser fluence could help enhance the laser cleaning effects and complete

12 cleaning threshold of laser cleaning painting layer is $5 \mathrm{~J} / \mathrm{cm}^{2}$. The resulting surface indicates that

13 the cleaning effects have positive correlation with laser fluence. Moreover, if the laser fluence

14 increases to initial cleaning threshold, the painting layers begin to remove and there exists some

15 traces on the surface. In contrast, if the laser fluence enhances to complete cleaning threshold, the

16 corresponding painting layers are peeled off thoroughly. As noted earlier, the enhancement of laser

17 fluence could promote the behavior of molecules thermodynamic and a host of process, the

18 resultant surface is agreed well with previous study [11]. Compared with the laser cleaned surface

19 at fluence of $5 \mathrm{~J} / \mathrm{cm}^{2}$, it can be found craters and tracks clearly in black color after the laser cleaning

20 at a laser fluence of $7 \mathrm{~J} / \mathrm{cm}^{2}$, which is mainly due to existing the excessive ablation upon laser

21 cleaned surface. This may be attributed to the photothermal effects play a prominent role in the 
1 laser cleaning at a laser fluence of $7 \mathrm{~J} / \mathrm{cm}^{2}$ and the resultant surfaces may experience the

2 evaporation, melting, re-solidification and ablation in an iterative dynamic process, which in turn

3 further lead to the excessive ablation.

$4 \quad$ Fig. 3 exhibits a low magnification secondary electron SEM image of the micro-morphology

5 of laser cleaned painting layer at varying laser fluence, including $2 \mathrm{~J} / \mathrm{cm}^{2}, 5 \mathrm{~J} / \mathrm{cm}^{2}$ and $7 \mathrm{~J} / \mathrm{cm}^{2}$

6 respectively. For the captured surfaces observed in Fig. 3 (a), the employed laser fluence was 2

$7 \mathrm{~J} / \mathrm{cm}^{2}$ and it can be found there are some cracks and concaves exposed on the surface of laser

8 cleaned surface, which is mainly due to the local temperature increase, viz. the enhanced lattice

9 vibration induced cracking result in the temperature enhancement, which is coincide with the

10 mechanism of the UV laser cleaning, namely, the photochemical interaction reactions between the

11 laser and the painting layer. As noted from Fig. 3 (d), instead of concaves and cracks, relatively

12 smooth and evenly surface, viz. some corrugated shape morphology can be presented from the

13 images, which indicates laser fluence reaching the cleaning threshold of the painting layer and

14 without destroying the underlying substrate. The corrugated shape morphology is well agreed with

15 a metallic luster surface of the substrate noted in Fig. 2 (c), which is suggested that it is a

16 thoroughly completely removal. As well, it is worth mentioning here that there are some ring-

17 shaped microstructures showing up in Fig. 3 (g). It is mainly due to the fact that the laser fluence

18 exceeding the theoretical threshold considerably, which triggers the phase change of the substrate,

19 followed by producing the ring-shaped microstructures. This is supported by the previous results

20 [46]. Notably, there are many craters in each laser cleaned surface, as noted in Fig. 3, which may

21 explain through the following: the AH36 steel substrate contains hydrogen. As for the UV laser 
1 cleaning the surface of painting layer, it experiences melting, evaporation, rapid solidification and

2 re-solidification as well as the corresponding hydrogen precipitates from the surface, followed by

3 the formation of hydrogen. This is also supported by prior research results [5, 47]. In what follows,

4 the craters cannot be filled with the liquid metal immediately, therefore it generates various craters

5 microstructure on the surface of AH36 steel substrate.

\section{$6 \quad 3.2$ Surface element distribution}

7 For evaluating the laser cleaning painting layer effects, the energy dispersive X-ray

8 spectroscopy (EDS) is widely recognized as a general method to examine the chemical

9 composition. One notes from Fig. 4 that it exhibits the corresponding elements content in the

10 marked black box straightforwardly and the percentages of weight at varying laser fluence are

11 expressed in Table 3. Together with the EDS analysis of the UV laser cleaned surface, the authors

12 find that Fe element weight percentage is $53.04 \%$ and oxygen is $5.58 \%$ in weight percentage in

13 area A. As noted from Figs. 4 (a) and (b), compared with area A, the area B in the Fe and O

14 element both have dramatically enhancement, which indicates area B has a relatively cleaned

15 surface and exposed more substrate surface than area A. As seen therein, the process of area A

16 belongs to incompletely cleaning period, whereas area B indicates it is a completely cleaning

17 process, which is well agreed with the earlier mentioned Fig. 3 (a) and (d), respectively. As for

18 area $\mathrm{C}$, it can be seen that the weight of $\mathrm{C}$ and $\mathrm{O}$ element higher than that of the area $\mathrm{A}$ and $\mathrm{B}$,

19 which suggests the area experiences excessive ablation and the corresponding iron oxide registers

20 the ring-shaped microstructure. This is also agreed well with the aforementioned Fig. 3 (g)

21 phenomena, including the ring-shaped microstructure and the excessive ablation effects. 
To reveal the surface element distribution more clearly, the line EDS is performed to

2 investigate changes of Fe, $\mathrm{O}, \mathrm{C}$ content along with some trace amounts of $\mathrm{Cr}$ and Ti. Fig. 5 (a), (b)

3 and (c) exhibit the line EDS report of element changes in the resulting laser cleaned area at varying

4 laser fluence of $2 \mathrm{~J} / \mathrm{cm}^{2}, 5 \mathrm{~J} / \mathrm{cm}^{2}$ and $7 \mathrm{~J} / \mathrm{cm}^{2}$ respectively. From the curves, it can be observed that

5 the Fe Kal appeared in (a) and (c) oscillates significantly more than (b), which is mainly due to

6 the laser cleaned surface (b) is relatively flat, viz. painting layer has been peeled off from the

7 substrate completely. Interestingly, it can be found there are some periodic curves appearing in the

8 line EDS examined surface in Fig. 5 (a). This indicates that the produced the ring-shaped

9 microstructure, namely, iron oxide is approximately periodic, which is due to the UV laser satisfied

10 the Gaussian distribution.

11 One notes from Fig. 6 (a) that presents a secondary electron SEM image of UV laser cleaned

12 surface morphology and manifests as disparate contrasts areas thoroughly. In Fig. 6 (b-g), it can

13 be observed certain specific elements including $\mathrm{Fe}, \mathrm{O}, \mathrm{C}, \mathrm{Ni}, \mathrm{Cr}$, and $\mathrm{Mo}$ are distributed on the

14 surface with various colors. From the mapping of the AH36 steel substrate surface, it is presented

15 the distribution of $\mathrm{Fe}, \mathrm{O}$ and $\mathrm{C}$ is the major elements on the surface, which is mainly due to $\mathrm{Fe}$ and

$16 \mathrm{C}$ elements are the prominent elements of substrate and there may exist the laser ablation during

17 the laser cleaning period. Clearly, from the mapping, it can be seen the distribution of the $\mathrm{O}$ and $\mathrm{C}$

18 is relatively homogeneous. As per the surface morphology of laser cleaned surface, it is suggested

19 that the convex exposed on the laser cleaned surface is rich in the $\mathrm{O}$ and $\mathrm{C}$ elements, whereas they

20 are almost absent in the center. This may be attributed to the UV laser satisfied Gaussian

21 distribution and the energy density at the center of the spot is greater than that at the edge, which 
1 results in the $\mathrm{O}$ element exposed in the center much more the edges. That is the reason why the

2 microstructure could generate the ring-shaped microstructure and corrugated shape morphology

3 respectively. Herein, the present findings are very encouraging and it can also infer that the

4 nanosecond UV laser could successfully strip off the painting layer thoroughly.

$5 \quad 3.3$ Mechanical properties analysis

$6 \quad$ 3.3.1 Hardness characterization

7 It is widely recognized that evaluate the mechanical properties exactly, the hardness

8 characterization is an indispensable, essential evaluation index, which needs to be considered

9 during the UV laser cleaning the painting layer. In this study, the Vickers microhardness test is

10 performed to investigate the mechanical properties, the details including the load of $290 \mathrm{~g}$ and

11 holding time duration of $15 \mathrm{~s}$, which can be demonstrated in Fig. 7. As such, from the curves, it

12 can be noticed that the UV laser cleaned surface increases to $150 \mathrm{HV}$ while the uncleaned surface

13 is $92 \mathrm{HV}$. As for the dramatically microhardness enhancement can be attributed to the fact that the

14 UV laser cleaned surface shows up rapid melting and quenching, which is followed by generating

15 the microstructure, including ring-shaped and corrugated shaped. The other reason is due to the

16 fact that the UV laser cleaning could induce the resultant surface producing dislocation density,

17 while the traditional cleaning techniques are not available. This is supported by the previous results

$18[17,48,49]$. Specifically, the standard deviation of laser cleaned surface and uncleaned surface

19 microhardness is 2.875 and 0.525 , respectively. Due to the painting layer uneven, the maximum

20 Vickers microhardness UV laser cleaned surface is $178 \mathrm{HV}$ and the minimum is $150 \mathrm{HV}$. Thus, it

21 is suggested that UV laser cleaning painting layers could enhance the surface microhardness 
1 considerably. Aside from the environmentally friendliness, this is another reason why authors take

2 this prospective method to remove the painting layer.

$3 \quad 3.3 .2$ Tensile and bending characterizations

4 For further investigating the tensile and bending properties of laser cleaned surface, there are

5 batches of standard tensile and bending test specimen produced by UV laser cleaning method. The

6 commensurately tensile stress and strain curves are illustrated in Fig. 8. From the curves, it can be

7 exhibited five stages in these tensile curves, such as elastic deformation, yield deformation, plastic

8 deformation, necking and fracture respectively [50-56]. The curves are just like the parabolic shape

9 and there is a rapid increase in the elastic and yield deformation stages. Followed by gradually

10 enhanced to the plastic deformation stage, there exist maximum values, viz., ultimate strength

11 appearing before reaching necking period, along with the reduction to facture stage sharply.

12 Notably, the tensile strength of laser cleaned surface is much stronger than that of before cleaning,

13 which is mainly due to the laser treatment is conducive to enhance the elastic and plastic

14 deformation properties of the substrate.

15 As for bending properties, it is widely recognized bending displacements and bending stress

16 are essential factors, which can be exhibited in Fig. 9. As noted in the curves, it can be observed

17 that both of the resulting laser cleaned surface and uncleaned surface experience complete elastic

18 deformation and plastic deformation stage, whereas the fracture stage does not exist in the sample,

19 in spite of the bending angles exceeding $90^{\circ}$ and bending stress over $1000 \mathrm{MPa}$. In this regard, it

20 indicates that both of the laser cleaned surface and uncleaned surface have excellent bending

21 strength and plasticity. Yet, laser cleaned surface manifests as better plasticity in the plastic 
1 deformation stage. Thus, the laser cleaned surface conduces to improve the bending strength and

2 plasticity properties.

$3 \quad$ 3.3.3 Roughness and profile characterizations

4 As seen in Fig. 10, it presents typical 3D morphologies along with corresponding line scanned

5 profiles of original painting layer and resulting laser cleaned surface, which is examined by optical

6 profiler and commensurately captured zone is $840 \mu \mathrm{m} \times 840 \mu \mathrm{m}$. As evident from Fig. 10 (a), it

7 can be seen that the original painting layer is relatively evenly and smooth, along with the surface

8 roughness $1.968 \mu \mathrm{m}$. Of particular note, white lines indicate maximum height difference is

9 approximately $10 \mu \mathrm{m}$ at original surfaces. With regard to the laser fluence $2 \mathrm{~J} / \mathrm{cm}^{2}$, the maximum

10 height difference is five times larger than that of the original painting layer surface and

11 corresponding surface roughness is $12.751 \mu \mathrm{m}$. This may be contributed to the laser energy is less

12 capable to remove the painting layer directly and there exists laser cleaning induced cracks and

13 concaves in this layer, which is well agreed with the prior mentioned Fig. 3 (a). Thus, the roughness

14 of laser cleaned surface at laser fluence $2 \mathrm{~J} / \mathrm{cm}^{2}$ increases dramatically. Specifically, as for laser

15 cleaned surface at laser fluence of $5 \mathrm{~J} / \mathrm{cm}^{2}$, the resultant surface is pretty smooth, viz. the surface

16 roughness is $2.471 \mu \mathrm{m}$ and relevant maximum height difference is approximately $6 \mu \mathrm{m}$, which

17 indicates laser fluence at $5 \mathrm{~J} / \mathrm{cm}^{2}$ is the most suitable for UV laser cleaning painting layers. As

18 such, it is suggested that laser cleaned surface at this fluence without destroying the underlying

19 substrate and the thermal ablation is minimal from the aforementioned surface morphology in Fig.

$20 \mathbf{3}(\mathrm{d})$. Therefore, laser fluence at $5 \mathrm{~J} / \mathrm{cm}^{2}$ is regarded as the threshold of UV laser cleaning painting

21 layer. To be noted here, the melted layer flowing and re-solidification forms a corrugated shape 
1 morphology, which coincides well with Fig. 3 (d). In comparison, the laser cleaned surface at laser

2 fluence $7 \mathrm{~J} / \mathrm{cm}^{2}$ has a relatively rough surface $(6.298 \mu \mathrm{m})$ and the maximum height difference is

3 about $27 \mu \mathrm{m}$, which is suggested that the surface experiences the excessive ablation and it is

4 consistent with the captured images in Fig. 3 (g). Thus, it is imperative to avoid the ablative

5 conditions occurred during UV laser cleaning painting layer as far as possible.

$6 \quad 3.4$ Theoretical model analysis

7 The experimental results illustrate initial cleaning threshold and complete cleaning threshold

8 based on laser and painting layer interactions. In order to explain the phenomena more detailly, it

9 is necessary to establish a thermodynamic model to describe the laser cleaning mechanism. Based

10 on the study of Zhang et al. [57], the theoretical relationship between the temperature and energy

11 are expressed as:

$12 \mathrm{E}=\mathrm{n} \cdot\left(\int_{T_{1}}^{T_{2}} c_{P} d T+\Delta \mathrm{H}\right)$

13 Herein, $T_{1}, T_{2}, n, C_{P}, \Delta H$ stand for initial temperature, final temperature, amount of 14 substance, heat capacity and molar heats of phase transition.

$15 c_{P}=A+B T+C T^{-2}$

16 Where, A, B, C are constants correlated with substance properties.

17 Based on the thermodynamic model, it is employed for theoretical calculation and the 18 corresponding assumptions are under following conditions:

19 (a) The painting layer and AH36 steel substrate are taken as heat insulators.

20 (b) The distribution of laser energy is homogeneous.

21 One notes from Fig. 11 that the schematic diagram of laser absorption and reflection. Wherein, 
$1 \mathrm{E}_{\mathrm{L}}, \mathrm{E}_{\mathrm{R}}, \delta_{1}, \delta_{2}$ indicate incident laser energy, reflection laser energy and thickness of painting

2 layer and substrate correspondingly. As well, $\mathrm{E}_{\mathrm{Fe}}, \mathrm{E}_{\mathrm{A}}, \mathrm{E}_{\mathrm{B}}$ are energy absorption of $\mathrm{Fe}$ substrate,

3 incident laser and reflection through painting layer respectively. $A_{a}$ and $A_{b}$ stand for laser

4 absorption coefficients of painting layer and Fe substrate respectively. The detailed equations are

5 shown as follows:

$6 \quad E_{A}=A_{a} \cdot E_{I}$

$7 \quad E_{F e}=A_{b} \cdot\left(E_{I}-E_{A}\right)$

$8 \quad E_{B}=A_{a} \cdot\left(E_{I}-E_{A}-E_{F e}\right)$

9 Herein, $\alpha_{1}$ and $\alpha_{2}$ are laser absorption coefficients of painting layer and Fe substrate

10 respectively. In addition, it can be calculated $\alpha_{1}=\left(1+\left(1-A_{a}\right) \cdot\left(1-A_{b}\right)\right) \cdot A_{a}, \alpha_{2}=(1-$

$\left.11 A_{a}\right) \cdot A_{b}$. As per Eq. (1), it can be obtained Eq. (6), as follows:

$12 \quad \alpha_{1} E_{I}=\frac{\rho_{1} \cdot s \cdot \delta_{1}}{M_{1}}\left(\int_{T_{1}}^{T_{2}} c_{P, \text { painting }} d T+\Delta H\right)$

13 Afterwards, the laser fluence can be deduced from Eq. (7) and the relationship is expressed

14 as:

$15 \quad F_{1}=\frac{\rho_{1} \cdot \delta_{1}}{\alpha_{1} M_{1}}\left(\int_{T_{1}}^{T_{2}} c_{P, \text { painting }} d T+\Delta H_{\text {painting }}\right)$

16 Correspondingly, the laser fluence of Fe substrate can be illustrated as follows:

$17 \quad F_{2}=\frac{\rho_{2} \cdot \delta_{2}}{\alpha_{2} M_{2}}\left(\int_{T_{1}}^{T_{2}} c_{P, F e} d T+\Delta H_{F e}\right)$

18 Wherein, $\rho_{1}, \rho_{2}, M_{1}, M_{2}$ are densities of painting layer and Fe substrate as well as molar

19 masses of painting layer and Fe substrate, respectively.

20 Inspired from Eqs. (7), (8) and substituted the corresponding physical constants shown in 
1 Table 4, it can be calculated the theoretical laser fluence is $1.789 \mathrm{~J} / \mathrm{cm}^{2}$ if temperature approaches

2 its melting points. As for the Fe substrate, it also can be derived from functions that laser fluence

3 are $3.216 \mathrm{~J} / \mathrm{cm}^{2}$ and $4.65 \mathrm{~J} / \mathrm{cm}^{2}$ with regard to the melting point and boiling point, respectively. It

4 is noteworthy that the calculated theoretically threshold $\left(4.65 \mathrm{~J} / \mathrm{cm}^{2}\right)$ is exceeded initial cleaning

5 threshold, which is mainly due to the fact that less consideration of the plasma shielding effects

6 and thermal expansion effects as well as various thickness of painting layer. These points will be

7 taken into account in future studies to modify this model effectively.

8 Comprehensively, the laser cleaning is a facile, environmentally friendly and promising

9 method to strip off the painting layer from the marine engineering surface. Hopefully, this study

10 would provide an experimental and theoretically analysis reference in the UV laser cleaning the

11 painting layer and pave the way for any further potential applications in industrial field.

\section{CONCLUDING REMARKS}

13 In this paper, a study based on the nanosecond UV laser cleaning method is innovatively

14 proposed, which is successfully utilized to strip off the painting layer from the AH36 steel substrate.

15 This study innovatively verifies the feasibility of the UV laser cleaning the painting layer on the

16 surface of AH36 steel in theory and briefly elaborates the primarily interaction mechanism of UV

17 laser, such as the photothermal and photochemical interactions. The thermal dynamic model is

18 established to describe the relationship between temperature and laser fluence, which indicates the

19 experimental results $\left(4.65 \mathrm{~J} / \mathrm{cm}^{2}\right)$ are close to theoretical cleaning threshold $\left(5 \mathrm{~J} / \mathrm{cm}^{2}\right)$ and the

20 differences between them are discussed exactly. Moreover, SEM, EDS, Optical profiler and 
1 mechanical tests are detailly performed to study the morphologies, chemical compositions and

2 mechanical properties of original painting layer surface and resulting laser cleaned surface at

3 varying laser fluence respectively. From the SEM test, there are some typical corrugated shaped,

4 craters and ring-shaped microstructures exhibited on the surface of laser cleaned surface at various

5 laser fluence. With regard to the mechanical properties, it is worth mentioning here that the UV

6 laser cleaned painting layer surface could enhance the surface microhardness, tensile strength and

7 bending strength dramatically. This can be attributed to the UV laser cleaned surface experiencing

8 rapid melting and quenching, followed by generating the ring-shaped and corrugated shaped

9 microstructure as well as the produced dislocation density. Therefore, this promising UV laser

10 cleaning method is not only environmentally friendly, but also enhances the mechanical properties

11 of laser cleaned surface significantly. Hopefully, there is a great potential to utilize this promising

12 method to large-scale cleaning the painting layer of the marine engineering surface and make some

13 contributions to the marine and industrial fields in the future.

\section{Acknowledgements}

15 This research is supported by the National Key Research \& Development Program (No.

16 2017YFB1105000) and Guangdong Province Key Area R\&D Program (No. 2018B090905003).

17 Yao Lu acknowledges the support and encouragement of Prof. Robert Fedosejevs at the University 18 of Alberta. 


\section{Author's contributions}

2 Yao Lu drafted this paper. Ye Ding and Maolu Wang supervise this manuscript. Lijun Yang

3 and Yang Wang edit this paper. All authors approve this paper.

\section{Declarations}

5 Ethical approval Not applicable

6 Consent to participate Not applicable

7 Consent to publication All presentations of case reports have consent for publication

\section{Declaration of Competing Interest}

9 The authors declare that they have no known competing financial interests or personal

10 relationships that could have appeared to influence the work reported in this paper. 


\section{REFERENCES}

2 [1] F.D. Zhang, H. Liu, C. Suebka, Y.X. Liu, Z. Liu, W. Guo, Y.M. Cheng, S.L. Zhang, L. Li,

3 Corrosion behaviour of laser-cleaned AA7024 aluminium alloy, Appl. Surf. Sci. 435 (2018) 452-

4461.

5 [2] T. Ze, Z.L. Lei, X. Chen, Y.B. Chen. Evaluation of laser cleaning for defouling of marine

6 biofilm contamination on aluminum alloys. Applied Surface Science 499 (2020): 144060.

7 [3] L.Y. Yue, Z.B. Wang, L. Li, Material morphological characteristics in laser ablation of alpha

8 case from titanium alloy, Appl. Surf. Sci. 258 (2012) 8065-8071.

9 [4] T. Ze, Z.L. Lei, X. Chen, Y.B. Chen. Nanosecond pulsed fiber laser cleaning of natural marine

10 micro-biofoulings from the surface of aluminum alloy. Journal of Cleaner Production 244 (2020):

11118724.

12 [5] T.Y. Shi, C.M. Wang, G.Y. Mi, F. Yan. A study of microstructure and mechanical properties of

13 aluminum alloy using laser cleaning. Journal of Manufacturing Processes 42 (2019): 60-66.

14 [6] Mhaede M. Influence of surface treatments on surface layer properties, fatigue and corrosion

15 fatigue performance of AA7075 T73. Mater Des 2012; 41:61-6.

16 [7] Qiang W, Guan Y, Cong B, Qi B. Laser cleaning of commercial Al alloy surface for tungsten

17 inert gas welding. J Laser Appl 2016;28(2).

18 [8] Z.Y. Zhang, J.Y. Zhang, Y.B. Wang, S.S. Zhao, X.C. Lin, X.Y. Li, Removal of paint layer by

19 layer using a $20 \mathrm{kHz} 140 \mathrm{~ns}$ quasi-continuous wave laser, Optik 174 (2018) 46-55. 
1 [9] M. Kumar, P. Bhargava, A.K. Biswas, S. Sahu, V. Mandloi, M.O. lttoop, B.Q. Khattak, M.K.

2 Tiwari, L.M. Kukreja, Epoxy-paint stripping using TEA CO2 laser: Determination of threshold

3 fluence and the process parameters, Opt. Laser Technol. 46 (2013) 29-36.

$4 \quad[10]$ Y. Lu, L.J. Yang, M.L. Wang, Y. Wang. Improved thermal stress model and its application in

5 ultraviolet nanosecond laser cleaning of paint. Applied Optics 59.25 (2020): 7652-7659.

6 [11] Y. Lu, Y. Ding, G.W. Wang, L.J. Yang. Ultraviolet laser cleaning and surface characterization

7 of AH36 steel for rust removal. Journal of Laser Applications 32.3 (2020): 032023.

8 [12] G. X. Chen, T. J. Kwee, K. P. Tan, Y. S. Choo, and M. H. Hong, High-power fiber laser

9 cleaning for green shipbuilding, J. Laser Micro/Nanoeng. 7, (2012), 249-253.

10 [13] G. X. Chen, T. J. Kwee, K. P. Tan, Y. S. Choo, M. H. Hong, Laser cleaning of steel for paint

11 removal, Appl. Phys. A (2010) 101, 249-253.

12 [14] J. A. Fox. Effect of water and paint coatings on laser-irradiated targets. Applied Physics

13 Letters 24.10 (1974): 461-464.

14 [15] K. Liu, and E. Garmire. Paint removal using lasers. Applied optics 34.21 (1995): 4409-4415.

15 [16] H.C. Zhao, Y.L. Qiao, X. Du, S.J. Wang. Laser cleaning performance and mechanism in 16 stripping of Polyacrylate resin paint. Applied Physics A 126 (2020): 1-14.

17 [17] J. Yang, J.H. Han, T. Duan, N.C. Sun, C. Guo, G.F. Feng. Mechanical analysis of paint film 18 stripping from aluminum plate surface by means of nanosecond laser. Laser Technol 37 (2013):

$19 \quad 718-722$. 
1 [18] X.K. Li, Q. Zhang, X. Zhou, D. Zhu, Q. Liu. The influence of nanosecond laser pulse energy

2 density for paint removal. Optik 156 (2018): 841-846.

3 [19] Y.L. Yao, H. Chen, W. Zhang. Time scale effects in laser material removal: a review. The

4 International Journal of Advanced Manufacturing Technology 26.5-6 (2005): 598-608.

5 [20] H.C. Zhao, Y.L. Qiao, Q. Zhang, X. Du, Y. Zang, X.T. Liu, B.Y. Han. Study on the 6 characteristics and mechanism of pulsed laser cleaning of polyacrylate resin coating on aluminum

7 alloy substrates. Applied Optics 59.23 (2020): 7053-7065.

8 [21] M.A. Jafarabadi, M.H. Mahdieh. Investigation of phase explosion in aluminum induced by

9 nanosecond double pulse technique. Applied Surface Science 346 (2015): 263-269.

10 [22] D.N. Patel, P. K. Pandey, R. K. Thareja. Stoichiometry of laser ablated brass nanoparticles in 11 water and air. Applied optics 52.31 (2013): 7592-7601.

12 [23] F. Vidal, T.W. Johnston, S. Laville, O. Barthélemy, M. Chaker, B. Le Drogoff, J. Margot, M.

13 Sabsabi. Critical-point phase separation in laser ablation of conductors. Physical review letters 1486.12 (2001): 2573.

15 [24] Q. H. Tang, D. Zhou, Y. L. Wang, G. F. Liu. Laser cleaning of sulfide scale on compressor 16 impeller blade. Applied Surface Science 355 (2015): 334-340.

17 [25] Han, D., Xu, J., Wang, Z., Yang, N., Li, X., Qian, Y., Li, G., Dai, R., Xu, S., Penetrating effect 18 of high-intensity infrared laser pulses through body tissue. RSC advances 8.56 (2018): 323441932357. 
1 [26] M. She, D. Kim, C. P. Grigoropoulos. Liquid-assisted pulsed laser cleaning using near-

2 infrared and ultraviolet radiation. Journal of applied Physics 86.11 (1999): 6519-6524.

3 [27] T.G. Kim, Y.S. Yoo, S.H. Lee, J.G. Park, Effects of size, humidity, and aging on particle

4 removal from Si wafers, Microelectron. Eng. 86 (2009) 145-149.

5 [28] J.H. Han, Cui X, Wang S, Feng G, Deng G, Hu R. Laser effects based optimal laser parameter

6 identifications for paint removal from metal substrate at $1064 \mathrm{~nm}$ : a multi-pulse model. Journal of

7 Modern Optics 64.19 (2017): 1947-1959.

8 [29] Temnov V.V., Sokolowski-Tinten, K., Zhou, P., El-Khamhawy, A., Von Der Linde, D., 9 Multiphoton ionization in dielectrics: comparison of circular and linear polarization. Physical 10 review letters 97.23 (2006): 237403.

11 [30] S. Amoruso, Modeling of UV pulsed-laser ablation of metallic targets. Applied Physics A 69.3

12 (1999): 323-332.

13 [31] Y. Lu, L.J. Yang, Y. Wang, H. Chen, B. Guo, Z. Tian. Paint Removal on the 5A06 Aluminum 14 Alloy Using a Continuous Wave Fiber Laser. Coatings, 9(8) (2019):488.

15 [32] Watkins, K.; McMahon, M.; Steen, W. Microstructure and corrosion properties of laser 16 surface processed aluminium alloys: A review. Mater. Sci. Eng. A (1997): 231, 55-61.

17 [33] Li, R.; Ferreira, M.; Almeida, A.; Vilar, R.; Watkins, K.; McMahon, M.; Steen, W. Localized 18 corrosion of laser surface melted 2024-T351 aluminium alloy. Surf. Coat. Technol. (1996), 81, $19290-296$. 
1 [34] W.F. Zou, Y.M. Xie, X. Xiao, X.Z. Zeng, Y. Luo. Application of thermal stress model to paint

2 removal by Q-switched Nd: YAG laser. Chinese Physics B 23.7 (2014): 074205.

3 [35] V. Oliveira, and R. Vilar. Finite element simulation of pulsed laser ablation of titanium carbide.

4 Applied surface science 253.19 (2007): 7810-7814.

5 [36] N.A. Vasantgadkar, U. V. Bhandarkar, S.S. Joshi. A finite element model to predict the ablation

6 depth in pulsed laser ablation. Thin Solid Films 519.4 (2010): 1421-1430.

7 [37] L.Y. Yue, Z.B. Wang, L. Li. Modeling and simulation of laser cleaning of tapered micro-slots

8 with different temporal pulses. Optics \& Laser Technology 45 (2013): 533-539.

9 [38] C.A. Aguilar, Y. Lu, S. Mao, S. Chen. Direct micro-patterning of biodegradable polymers

10 using ultraviolet and femtosecond lasers. Biomaterials 26.36 (2005): 7642-7649.

11 [39] N. Arnold, N. Bityurin, D. Bäuerle. Laser-induced thermal degradation and ablation of 12 polymers: bulk model. Applied Surface Science 138 (1999): 212-217.

13 [40] Srinivasan, V., Mark A. Smrtic, S. V. Babu. Excimer laser etching of polymers. Journal of 14 applied physics 59.11 (1986): 3861-3867.

15 [41] A. A. Serafetinides, C.D. Skordoulis, M.L. Maropoulou. Picosecond and subpicosecond 16 visible laser ablation of optically transparent polymers. Applied surface science 135.1-4 (1998):

$17 \quad 276-284$.

18 [42] Z. B. Wang, M.H. Hong, Y.F. Lu, D.J. Wu, B. Lan. Femtosecond laser ablation of 19 polytetrafluoroethylene (Teflon) in ambient air. Journal of applied physics 93.10 (2003): 6375- 
6380.

2 [43] Y. Lu, L.J. Yang, M.L. Wang, Y. Wang. Simulation of nanosecond laser cleaning the paint

3 based on the thermal stress. Optik (2020): 165589.

4 [44] R.R. Fang, D. Zhang, Z. Li, F. Yang, L. Li, X. Tan. Improved thermal model and its application

5 in UV high-power pulsed laser ablation of metal target. Solid State Communications 145.11-12

6 (2008): 556-560.

7 [45] D. VonderLinde, K. Sokolowski-Tinten. The physical mechanisms of short-pulse laser 8 ablation. Applied Surface Science 154 (2000): 1-10.

9 [46] Y. Lu, Y.C. Guan, Y. Li, Y. Wang, M.L. Wang. Nanosecond laser fabrication of 10 superhydrophobic surface on 316L stainless steel and corrosion protection application. Colloids 11 and Surfaces A: Physicochemical and Engineering Aspects 604 (2020): 125259.

12 [47] X.J. Wang, S.Y. Long. Study on hereditary of pores in laser remelting of die casting AZ91D

13 magnesium alloy. Acta Metall Sin 48.12 (2012): 1437-1445.

14 [48] Z.M. Wang, X.Y. Zeng, W.L. Huang. Parameters and surface performance of laser removal of 15 rust layer on A3 steel. Surface and Coatings Technology 166.1 (2003): 10-16.

16 [49] Y. Cui, J.Q. Shen, S.S. Hu. Microstructure and performance of the laser melted aluminum

17 bronze layers with and without using activator. Materials Research Express 6.6 (2019): 066513.

18 [50] Y. He, J. Wei, J.Y. Liu, Y. Wang. Experimental study on the fabrication profile and mechanical 19 properties by substrate-inclined angle using laser melting deposition (LMD) integrating with the 
1 substrate of stainless steel. Optics \& Laser Technology 125 (2020): 106038.

2 [51] W.D. Nix. Mechanical properties of thin films. Metallurgical transactions A 20.11 (1989):

32217.

4 [52] J.J. Lewandowski, M. Seifi. Metal additive manufacturing: a review of mechanical properties.

5 Annual review of materials research 46 (2016).

6 [53] B.X. Su, B. Wang, L. Wang, Y. Su, F. Wang. The corrosion behavior of Ti-6Al-3Nb-2Zr-1Mo

7 alloy: effects of $\mathrm{HCl}$ concentration and temperature. Journal of Materials Science \& Technology

8 (2020).

9 [54] B.X. Su, L. Luo, B. Wang, Y. Su, L. Wang. Annealed microstructure dependent corrosion 10 behavior of Ti-6Al-3Nb-2Zr-1Mo alloy. Journal of Materials Science \& Technology 62 (1920):

$11 \quad 234-248$.

12 [55] V. Crupi, E. Gulielmino, M. Maestro, A. Marino. Fatigue analysis of butt welded AH36 steel 13 joints: thermographic method and design S-N curve. Marine Structures 22.3 (2009): 373-386.

14 [56] J. Cheon, D.V. Kiran, S.J. Na. Thermal metallurgical analysis of GMA welded AH36 steel 15 using CFD-FEM framework. Materials \& Design 91 (2016): 230-241.

16 [57] G.X. Zhang, X.M. Hua, Ye Huang, Y.L. Zhang, Fang Li, Chen Shen, Jian Cheng. Investigation

17 on mechanism of oxide removal and plasma behavior during laser cleaning on aluminum alloy.

18 Applied Surface Science 506 (2020): 144666.

19 [58] David Gaskel, Introduction to the Thermodynamics of Materials, fourth ed., Taylor \& Francis, 
12003.

2 
FIGURE LIST

(a)
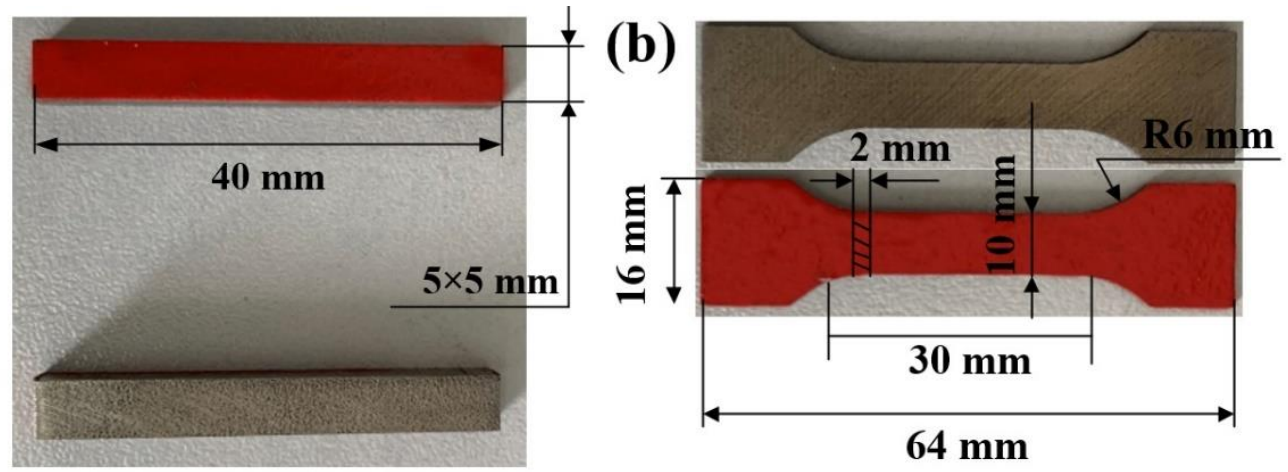

Fig. 1. (a) Standard Tensile Samples (b) standard Bending Samples.
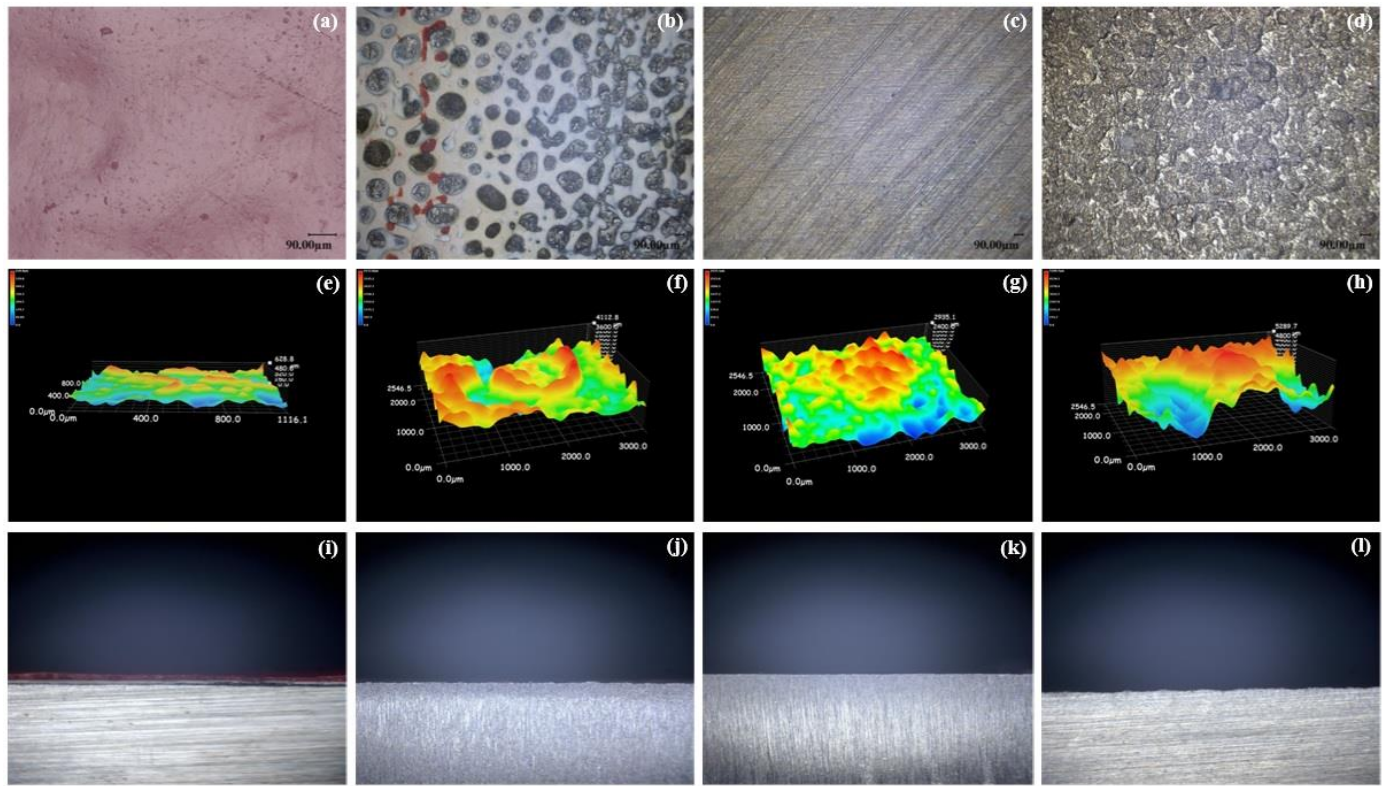

Fig. 2. Macroscopic three- and two-dimensional optical images of original surface (a, e, i) and laser cleaned surface at scanning speed of $1000 \mathrm{~mm} / \mathrm{s}$ with different fluence, among them $(b, f, j)$ at laser fluence of $2 \mathrm{~J} / \mathrm{cm}^{2}$, $(\mathrm{c}, \mathrm{g}, \mathrm{k})$ at laser fluence of $5 \mathrm{~J} / \mathrm{cm}^{2},(\mathrm{~d}, \mathrm{~h}, \mathrm{l})$ at laser fluence of $7 \mathrm{~J} / \mathrm{cm}^{2}$ respectively. 

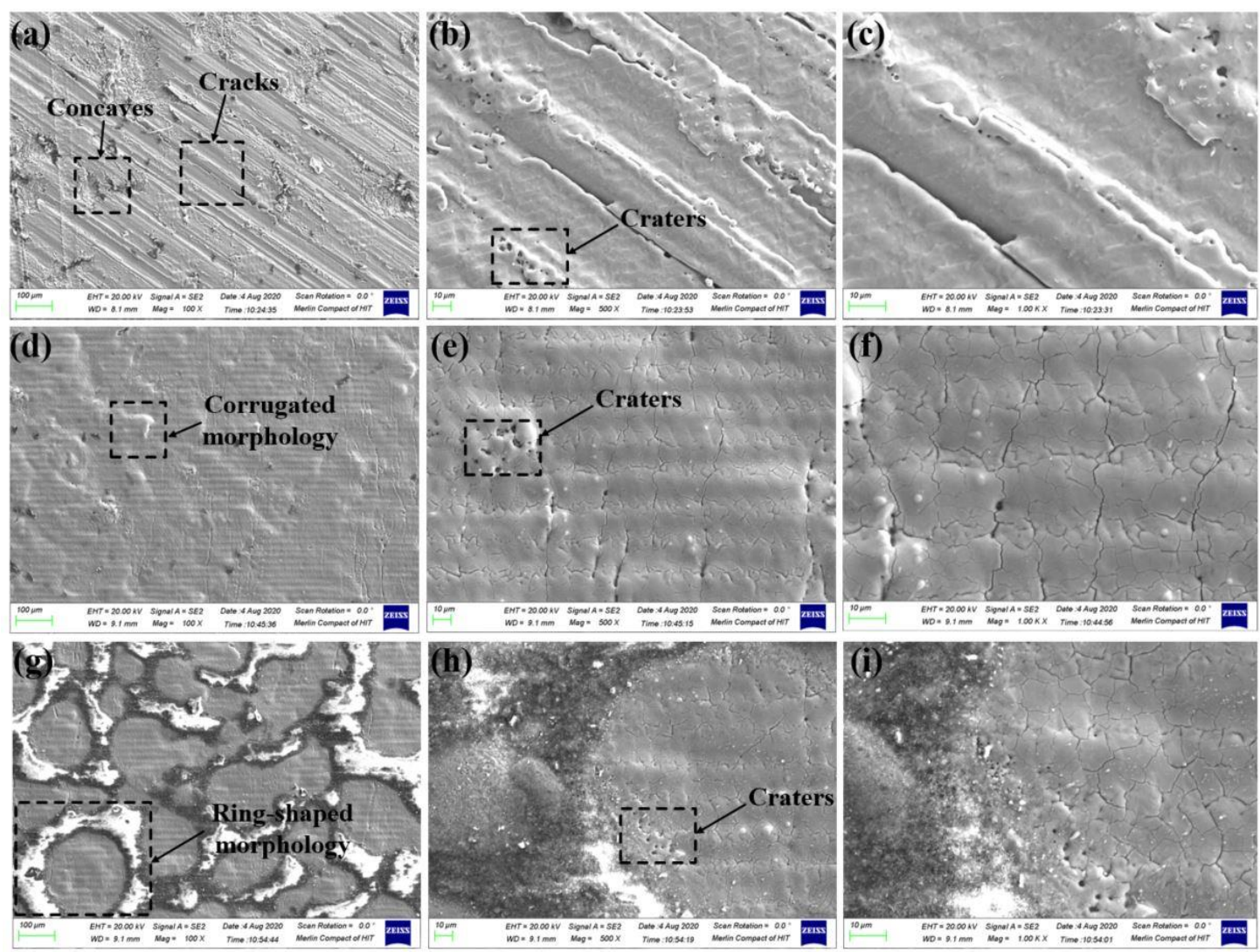

Fig. 3. SEM images of laser cleaned surface at different fluence (a) $2 \mathrm{~J} / \mathrm{cm}^{2}$ (d) $5 \mathrm{~J} / \mathrm{cm}^{2}$ (g) $7 \mathrm{~J} / \mathrm{cm}^{2}$, (b, c), (e, f) and $(\mathrm{h}, \mathrm{i})$ are the accordingly magnification images, correspondingly. 

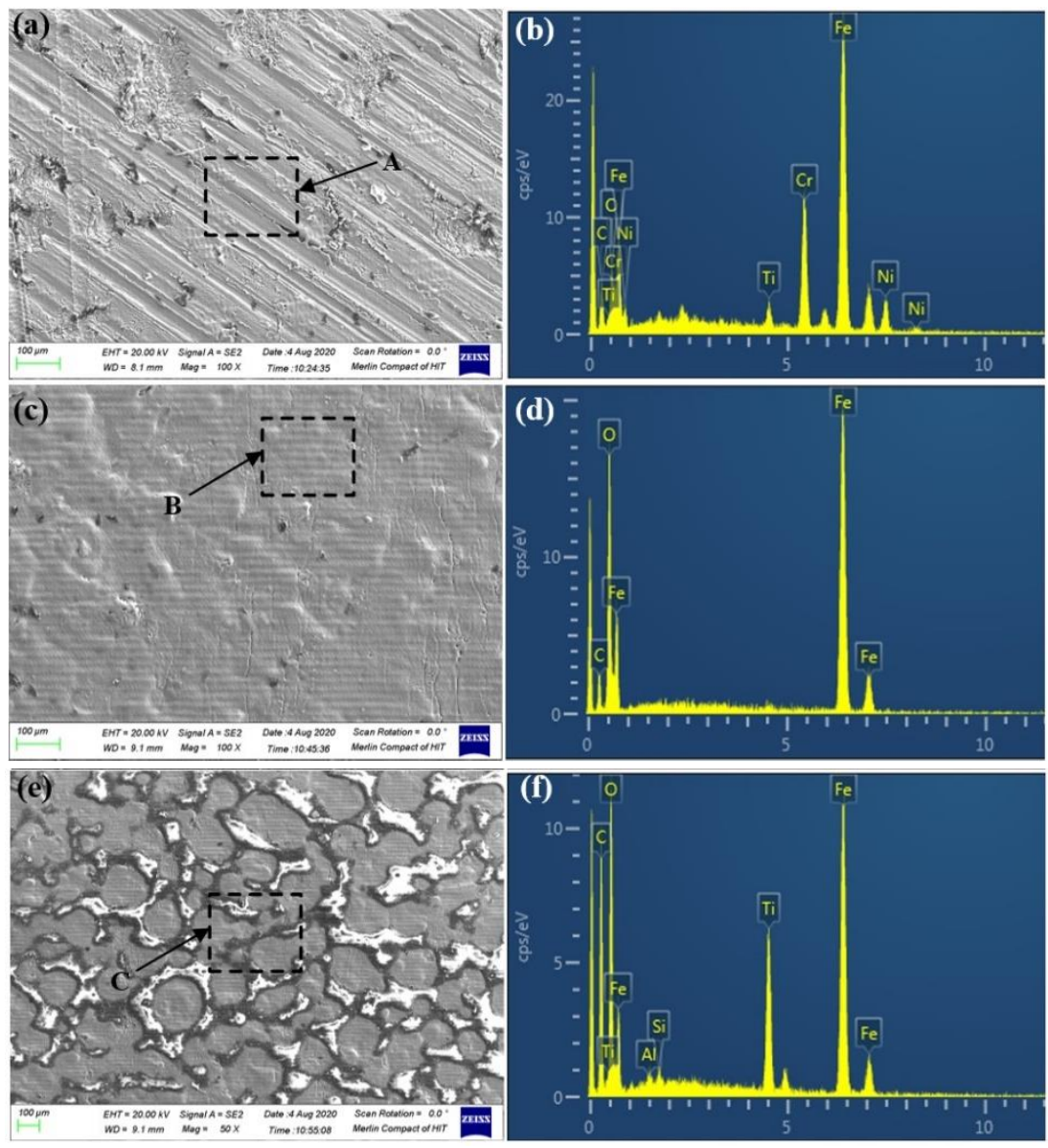

7 Fig. 4. SEM and EDS images of laser cleaned surface with various fluence (a) $2 \mathrm{~J} / \mathrm{cm}^{2}$ (c) $5 \mathrm{~J} / \mathrm{cm}^{2}$ (e) $7 \mathrm{~J} / \mathrm{cm}^{2}$,

(b)-(f) are the accordingly EDS images, respectively. 

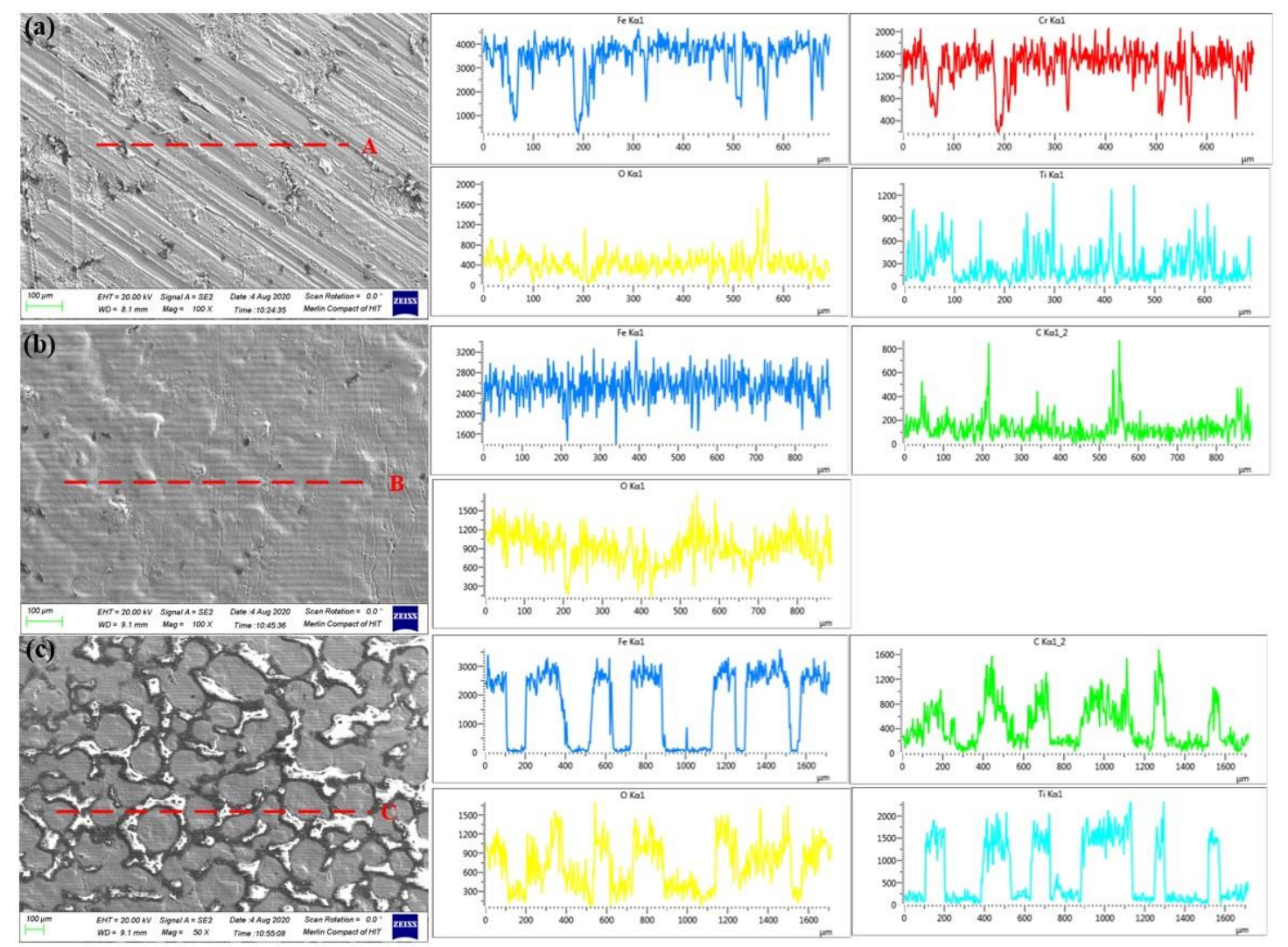

Fig. 5. Line EDS images of laser cleaned surface with different laser fluence (a) $2 \mathrm{~J} / \mathrm{cm}^{2}$ (b) $5 \mathrm{~J} / \mathrm{cm}^{2}$ (c) 7 $\mathrm{J} / \mathrm{cm}^{2}$, respectively.
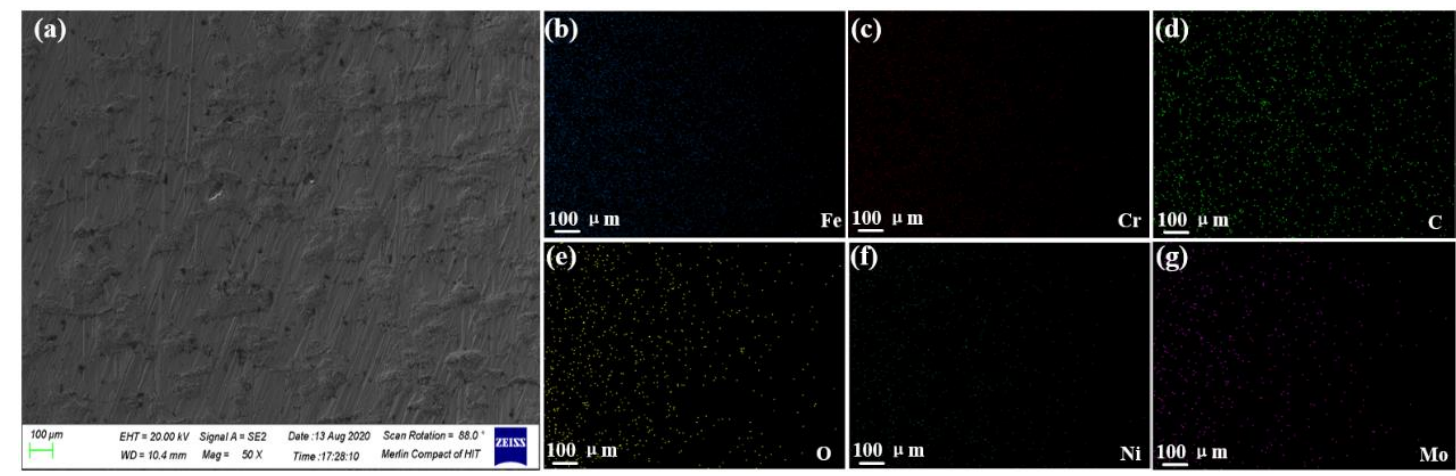

Fig. 6. SEM images of laser cleaned surface and (b)-(g) are the accordingly elemental distributions after laser cleaning, respectively. 


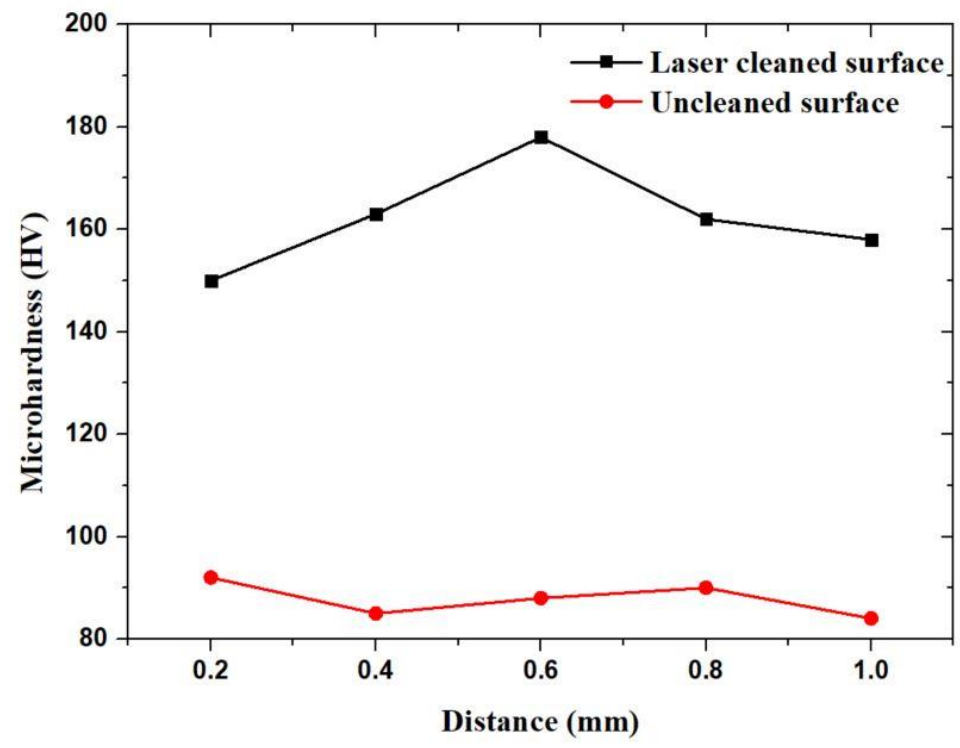

Fig. 7. The microhardness characterization after UV laser cleaning.

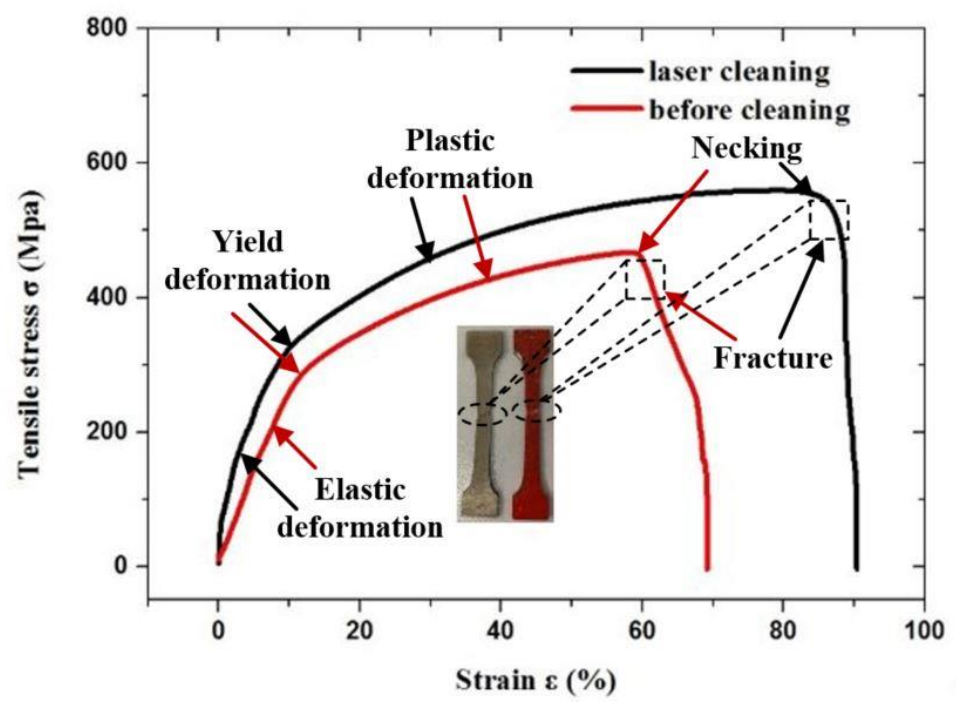

Fig. 8. The relationship between the strain and tensile stress. 


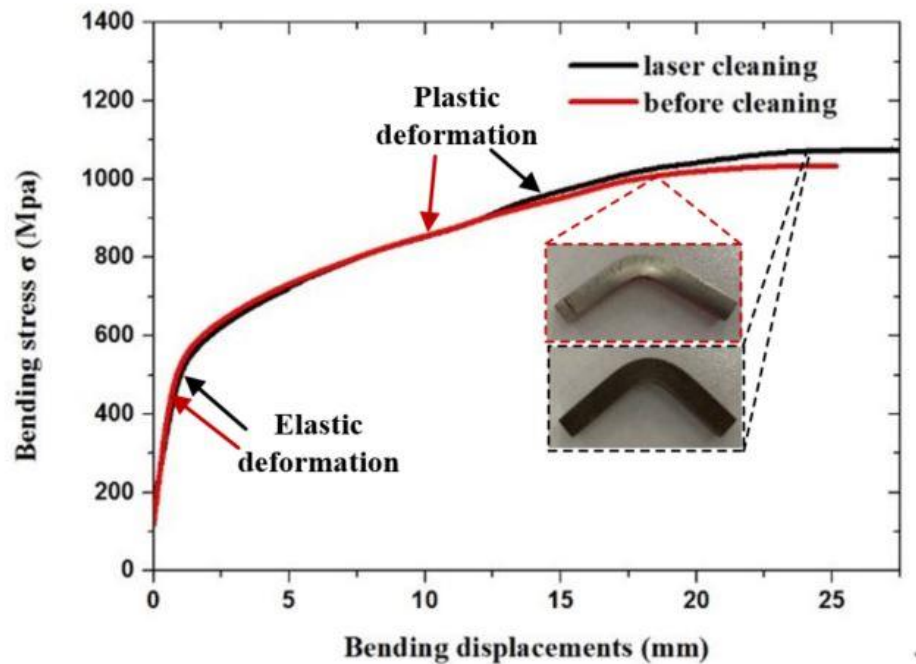

Fig. 9. The relationship between the bending displacements and bending stress. 

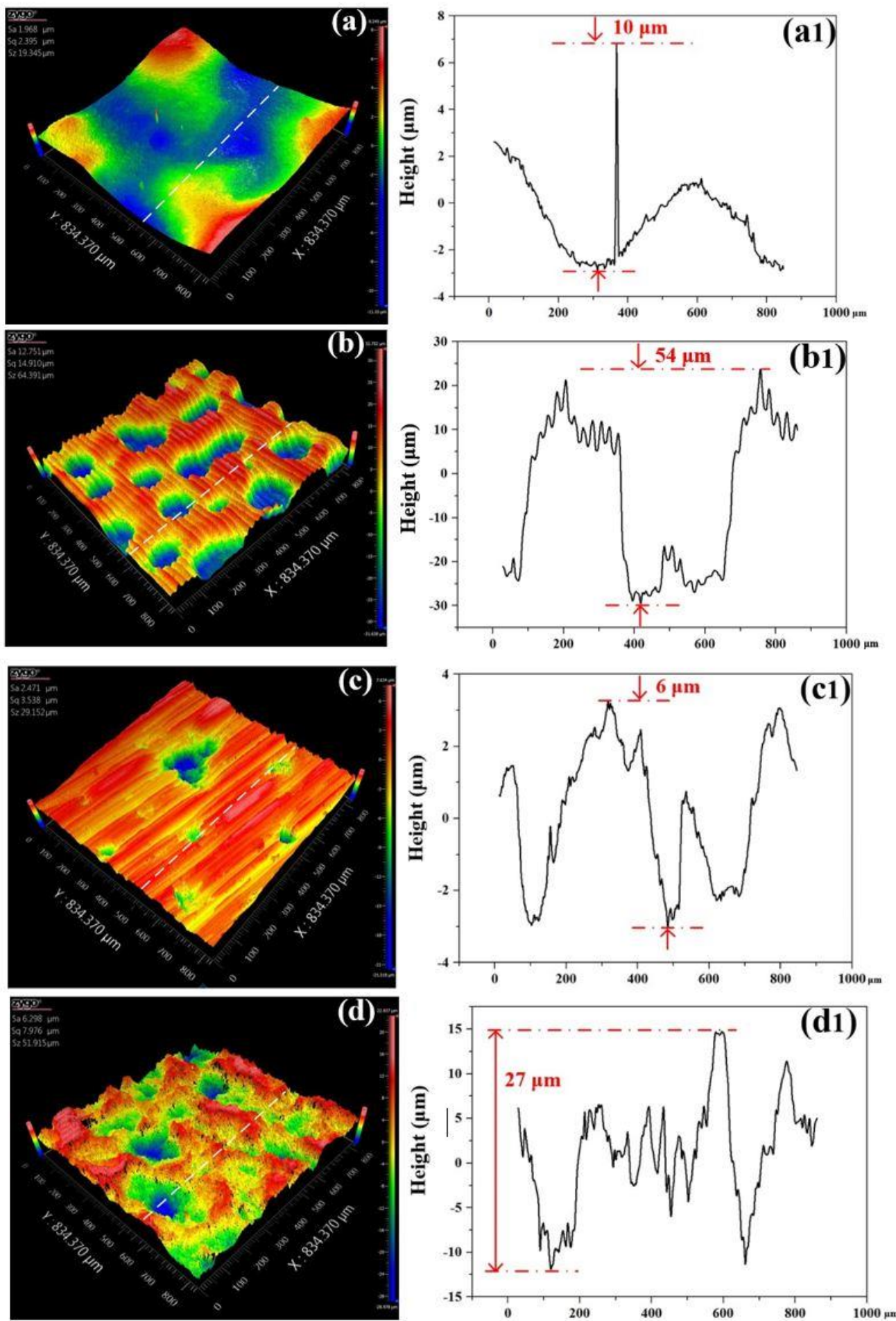

13 Fig. 10. Optical profiler 3D height images of laser cleaned painting layer surfaces (a) original painting layer 14 (b) laser cleaned surface at laser fluence $2 \mathrm{~J} / \mathrm{cm}^{2}$ (c) $5 \mathrm{~J} / \mathrm{cm}^{2}$ (d) $7 \mathrm{~J} / \mathrm{cm}^{2}$, (a1)-(d1) are the accordingly line scanned profiles, respectively. 


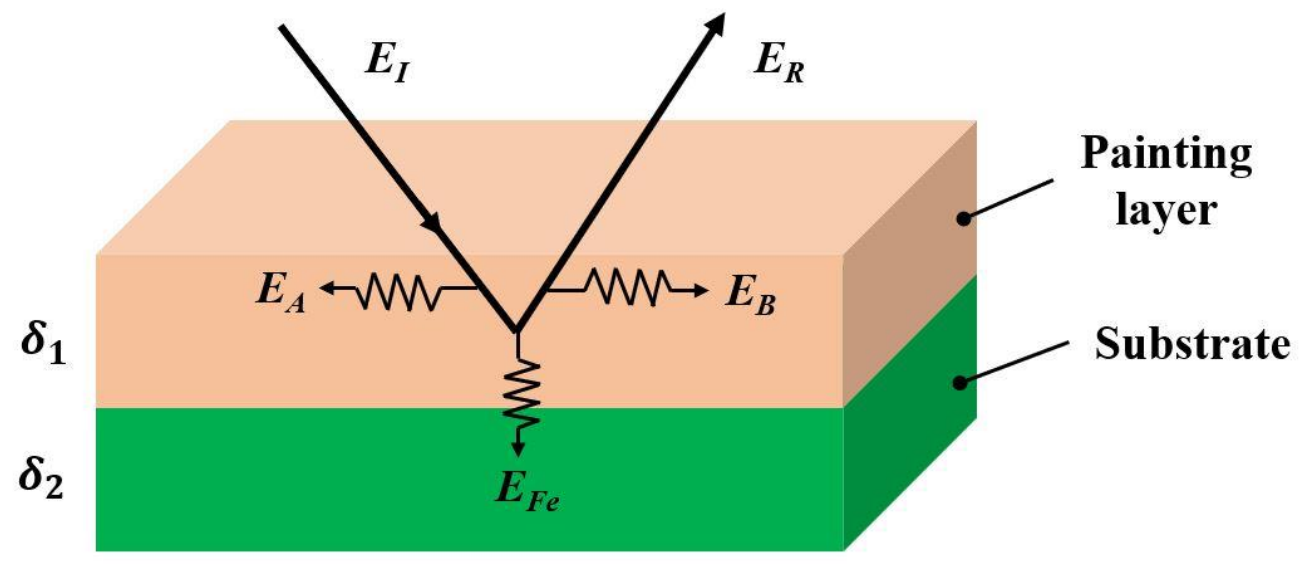

Fig. 11. Schematic diagram of laser cleaning painting layer model. 
TABLE LIST

Table 1. Mass fraction of elements in AH36 steel w\%.

\begin{tabular}{ccccccc}
\hline Elements & $\mathrm{Fe}$ & $\mathrm{Mn}$ & $\mathrm{Si}$ & $\mathrm{C}$ & $\mathrm{P}$ & $\mathrm{S}$ \\
\hline Mass fraction & base & $1.20-1.45$ & $0.15-0.50$ & $0.15-0.18$ & 0.025 & 0.1 \\
\hline
\end{tabular}

3

4

5

Table 2. Chemical bond energies of painting layer.

\begin{tabular}{ccccccc}
\hline Polymer bonds & $\mathrm{C}-\mathrm{N}$ & $\mathrm{C}-\mathrm{H}$ & $\mathrm{C}=\mathrm{C}$ & $\mathrm{O}-\mathrm{O}$ & $\mathrm{C}=\mathrm{O}$ & $\mathrm{C}-\mathrm{C}$ \\
\hline Bond energy & 3.04 & 4.30 & 8.44 & 5.12 & 6.40 & 3.62 \\
\hline
\end{tabular}

6

7

Table 3. The element composition measured by EDS of the laser cleaned painting layer surface with 3 different areas.

\begin{tabular}{cccc}
\hline element & $\mathrm{A}$ & $\mathrm{B}$ & $\mathrm{C}$ \\
\cline { 2 - 4 } & Weight $/ \%$ & Weight $/ \%$ & Weight $/ \%$ \\
\hline $\mathrm{C}$ & 17.41 & 12.89 & 30.67 \\
$\mathrm{O}$ & 5.58 & 24.50 & 27.67 \\
$\mathrm{Fe}$ & 53.04 & 62.61 & 32.43 \\
\hline
\end{tabular}

10

11

12

13

14

15

16

17

18

19

20

21

22

23

24

25

26

27

28 
Table 4. The physical constants of Fe substrate and painting layer [58].

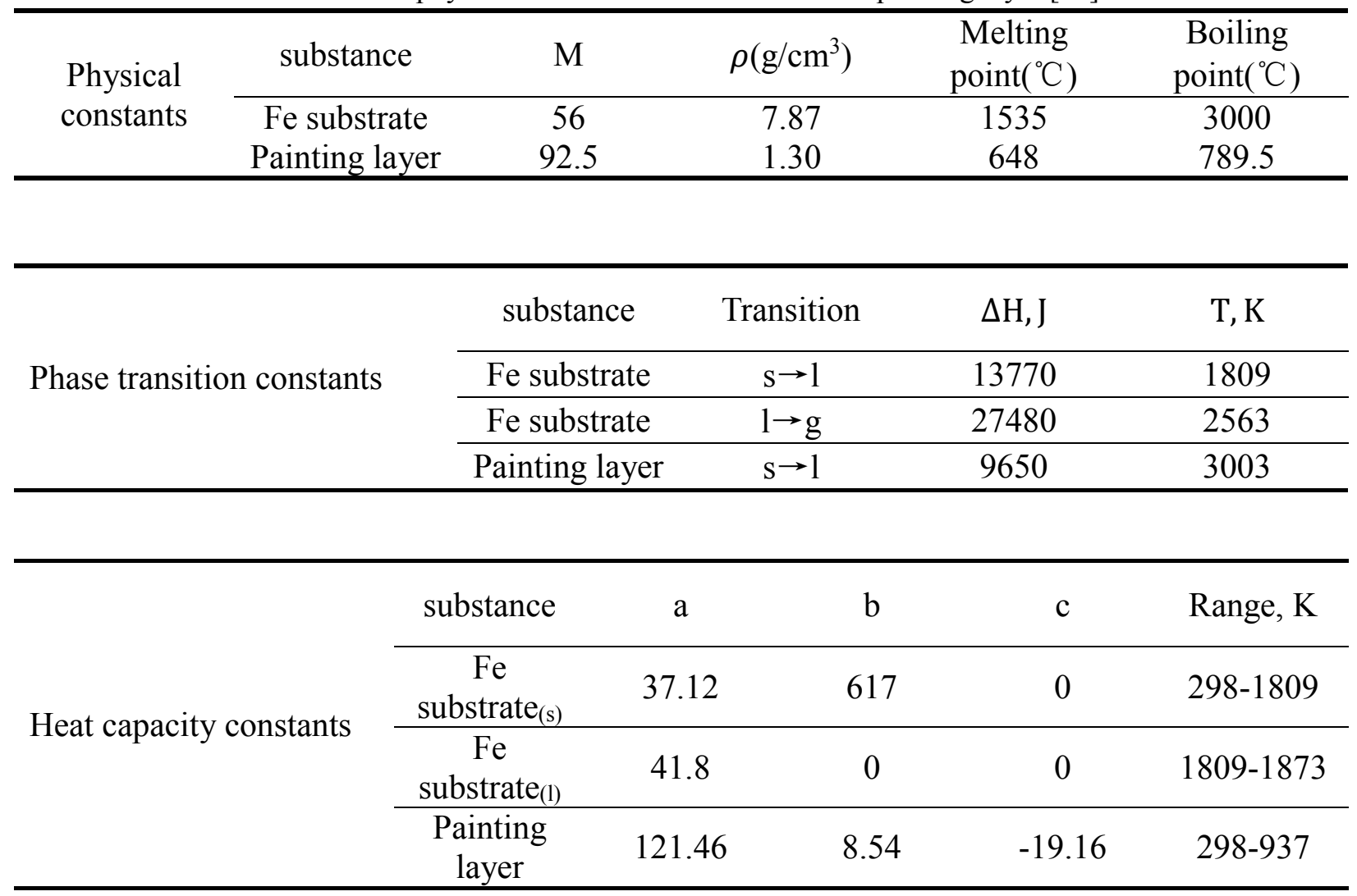

3

4 


\section{Figures}

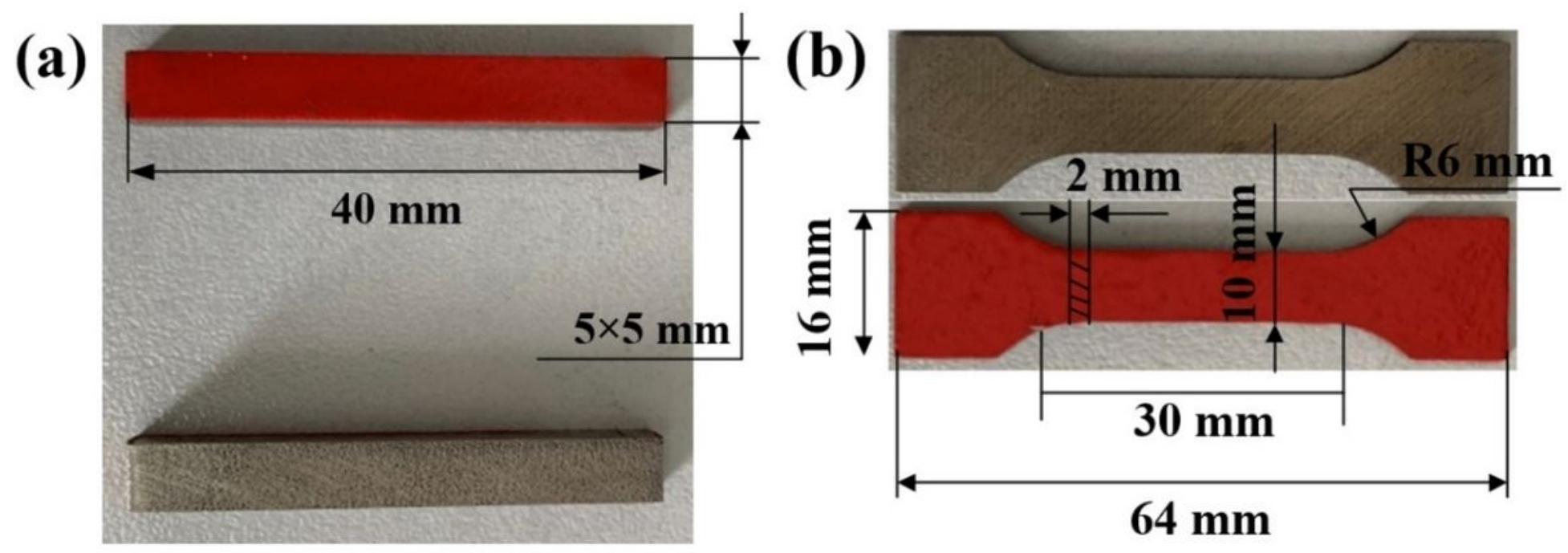

Figure 1

(a) Standard Tensile Samples (b) standard Bending Samples.
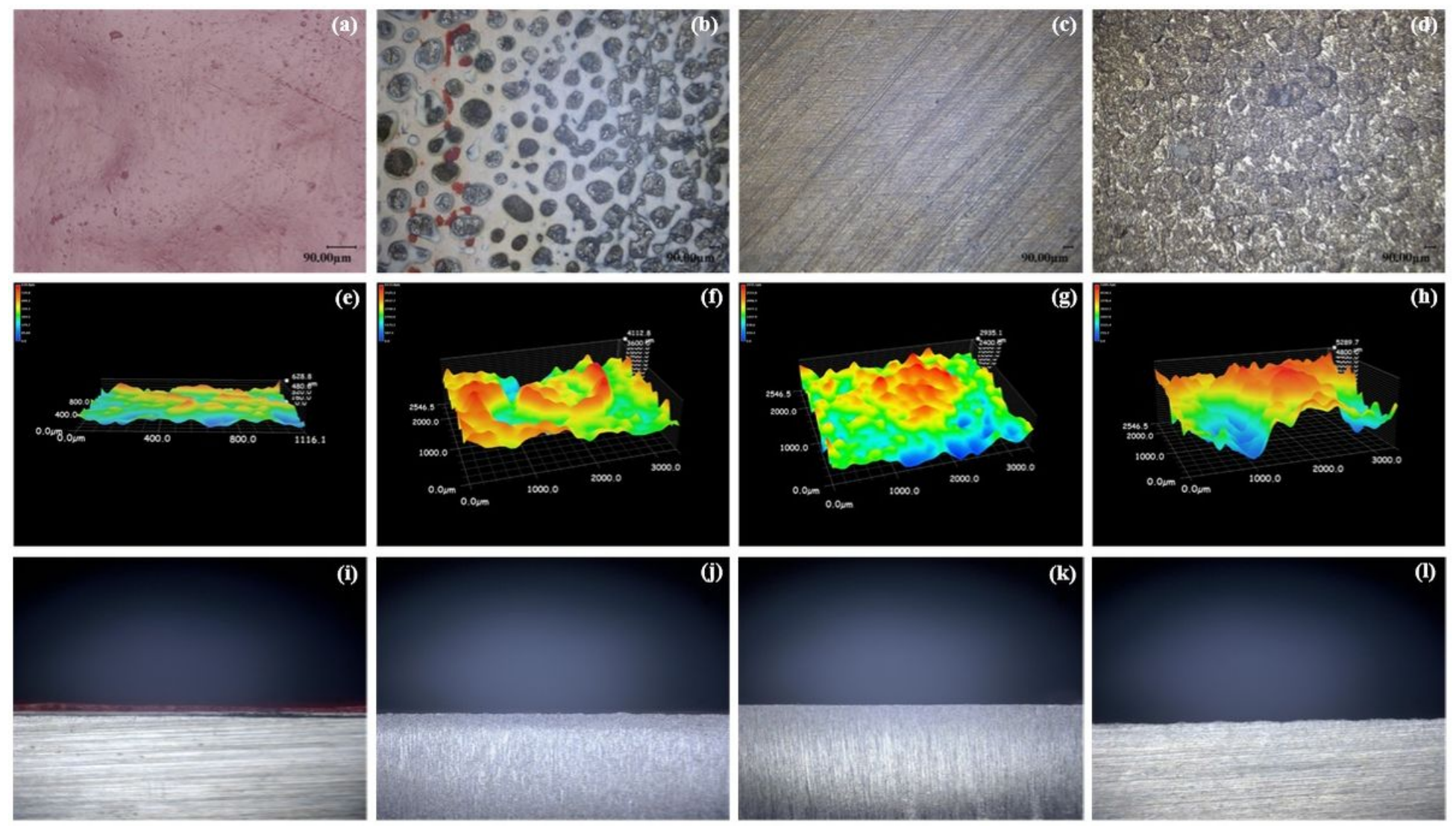

Figure 2

Macroscopic three- and two-dimensional optical images of original surface $(\mathrm{a}, \mathrm{e}, \mathrm{i})$ and laser cleaned surface at scanning speed of $1000 \mathrm{~mm} / \mathrm{s}$ with different fluence, among them $(b, f, j)$ at laser fluence of 2 $\mathrm{J} / \mathrm{cm} 2,(\mathrm{c}, \mathrm{g}, \mathrm{k})$ at laser fluence of $5 \mathrm{~J} / \mathrm{cm} 2,(\mathrm{~d}, \mathrm{~h}, \mathrm{l})$ at laser fluence of $7 \mathrm{~J} / \mathrm{cm} 2$ respectively. 

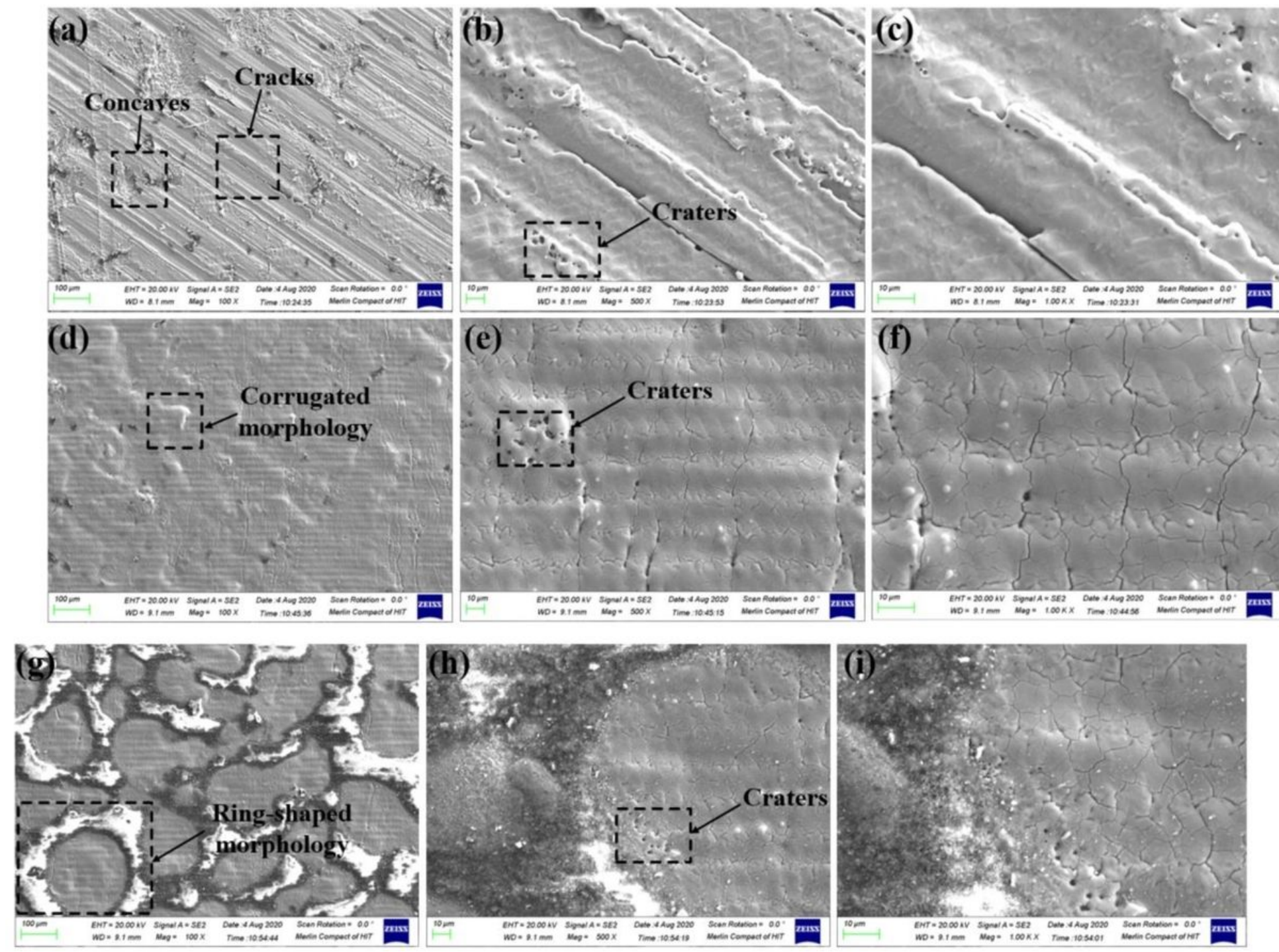

\section{Figure 3}

SEM images of laser cleaned surface at different fluence (a) $2 \mathrm{~J} / \mathrm{cm} 2$ (d) $5 \mathrm{~J} / \mathrm{cm} 2$ (g) $7 \mathrm{~J} / \mathrm{cm} 2$, (b, c), (e, f) and $(h, i)$ are the accordingly magnification images, correspondingly. 

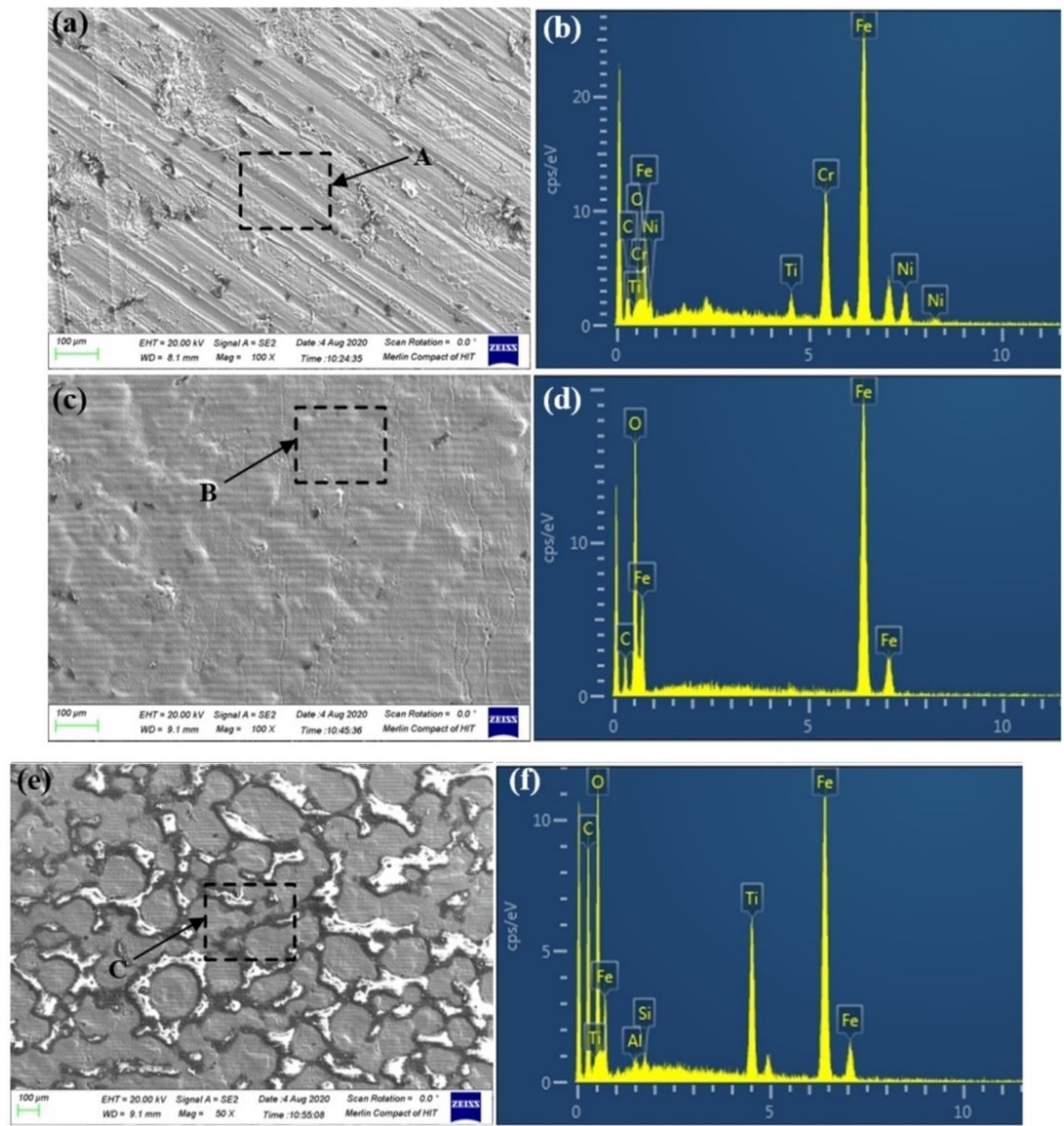

Figure 4

SEM and EDS images of laser cleaned surface with various fluence (a) $2 \mathrm{~J} / \mathrm{cm} 2$ (c) $5 \mathrm{~J} / \mathrm{cm} 2$ (e) $7 \mathrm{~J} / \mathrm{cm} 2$, (b)-(f) are the accordingly EDS images, respectively. 

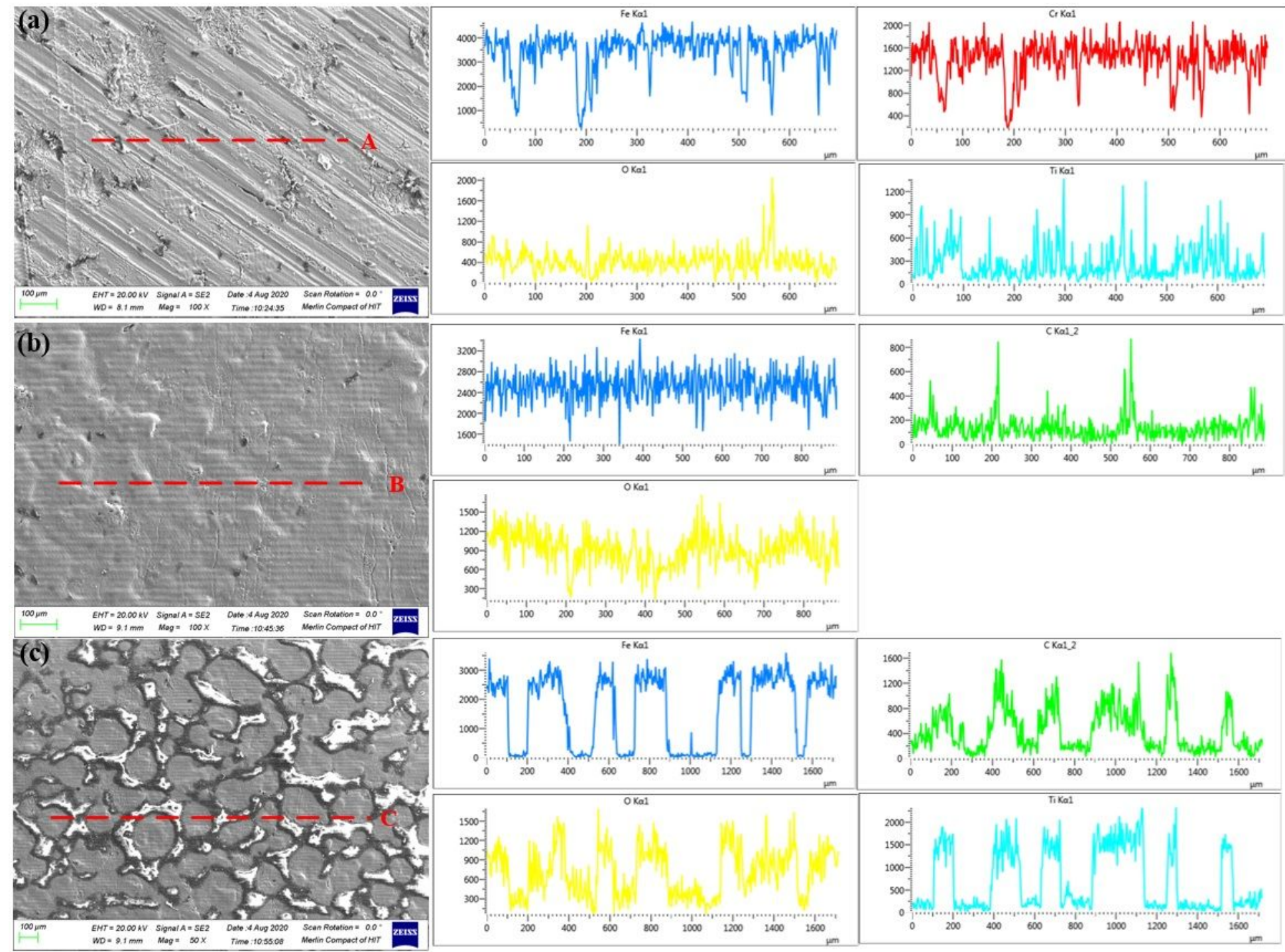

Figure 5

Line EDS images of laser cleaned surface with different laser fluence (a) $2 \mathrm{~J} / \mathrm{cm} 2$ (b) $5 \mathrm{~J} / \mathrm{cm} 2$ (c) 7 $\mathrm{J} / \mathrm{cm} 2$, respectively.

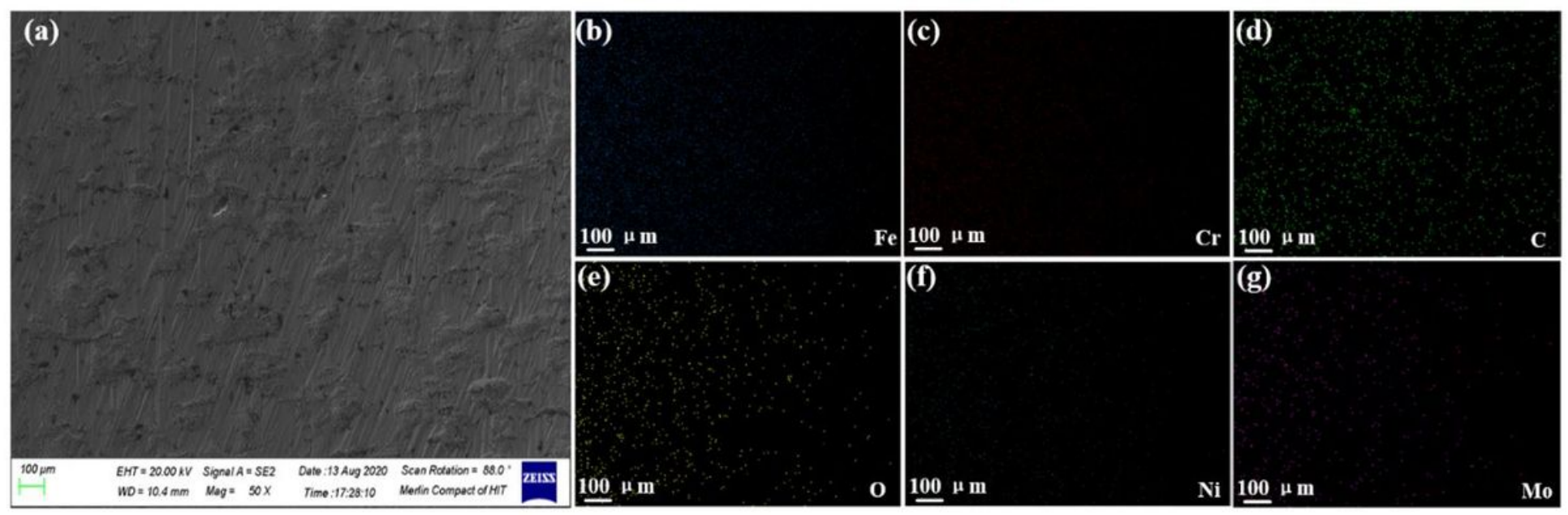


SEM images of laser cleaned surface and (b) $-(\mathrm{g})$ are the accordingly elemental distributions after laser cleaning, respectively.

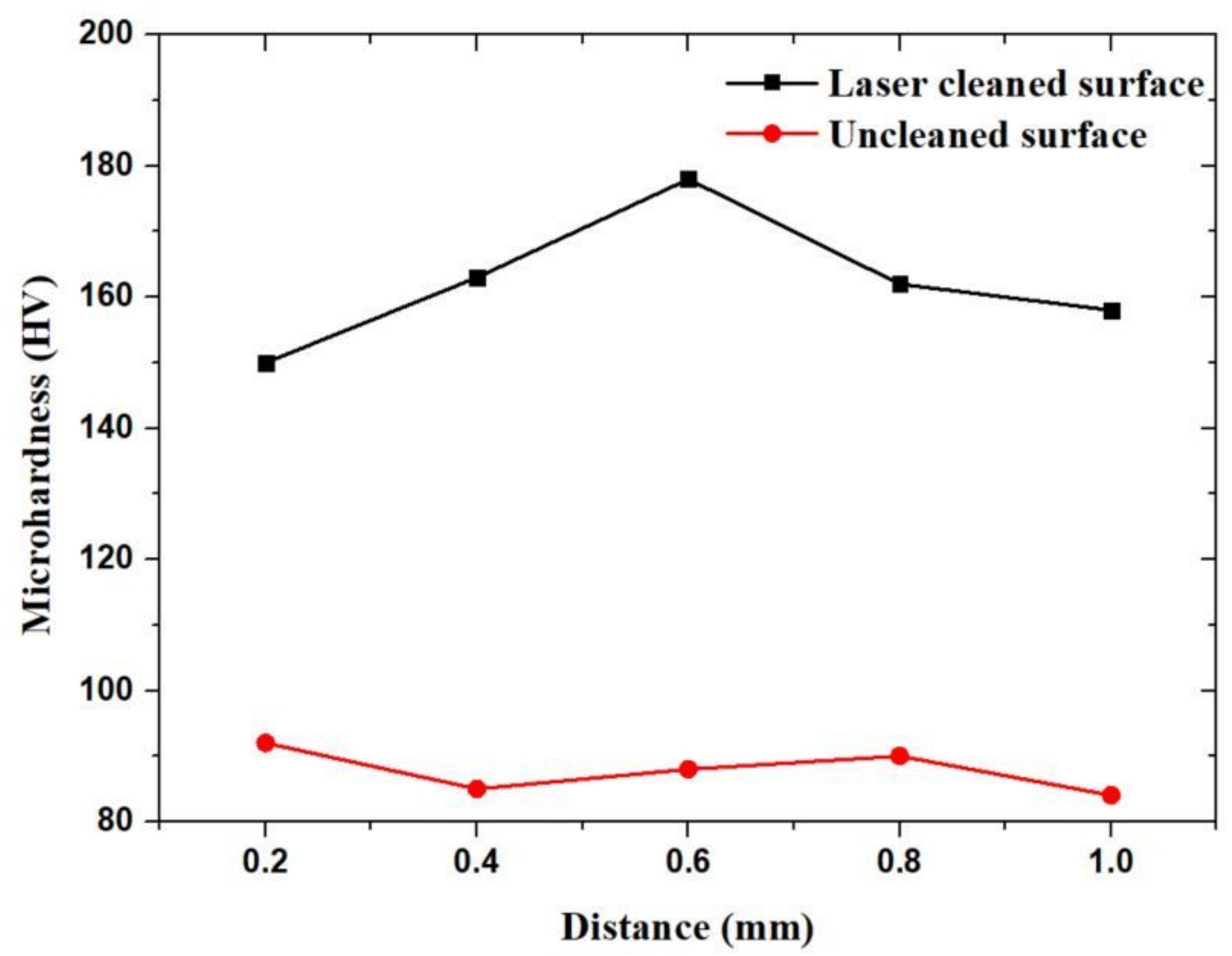

Figure 7

The microhardness characterization after UV laser cleaning. 


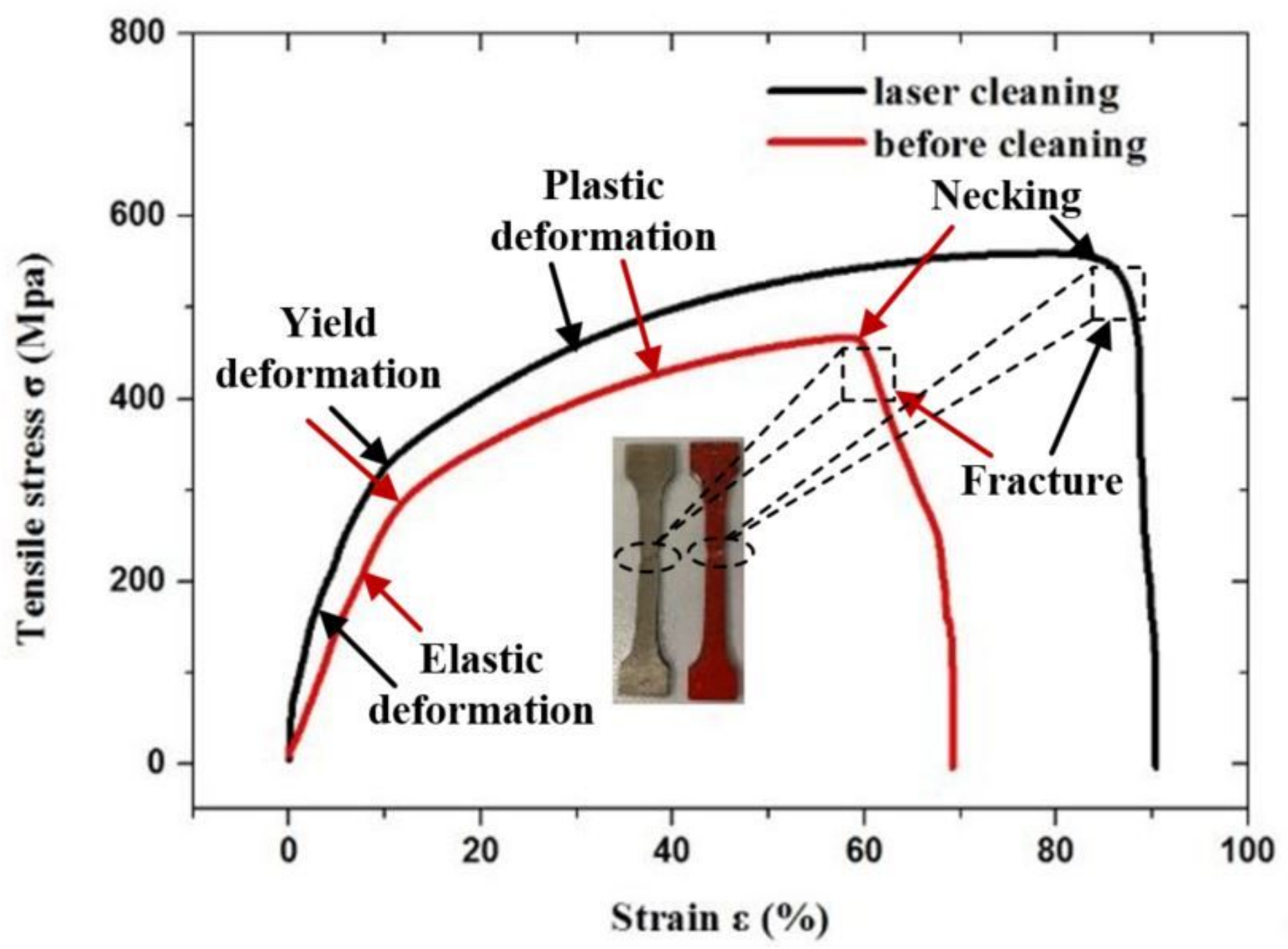

Figure 8

The relationship between the strain and tensile stress. 


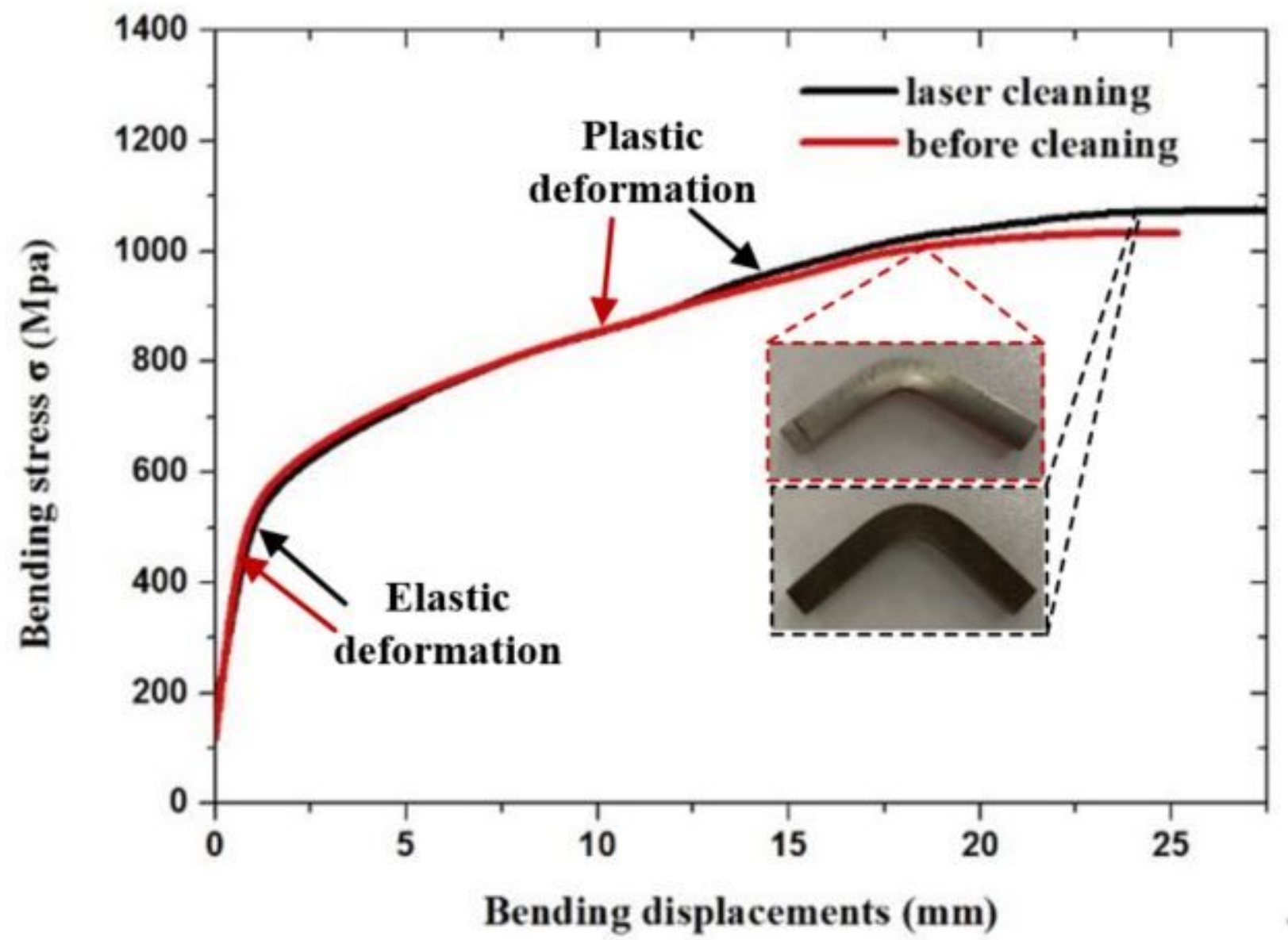

Figure 9

The relationship between the bending displacements and bending stress.

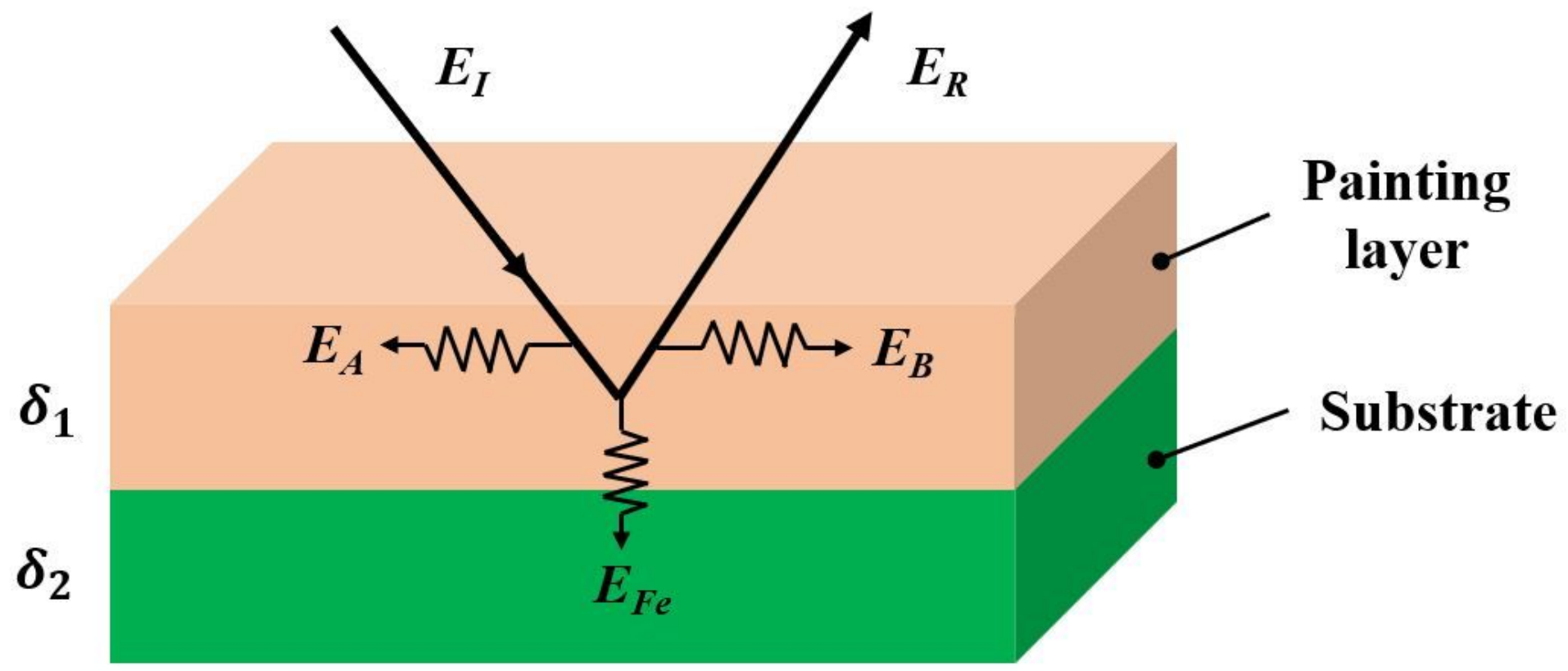

Figure 11 
Schematic diagram of laser cleaning painting layer model. 